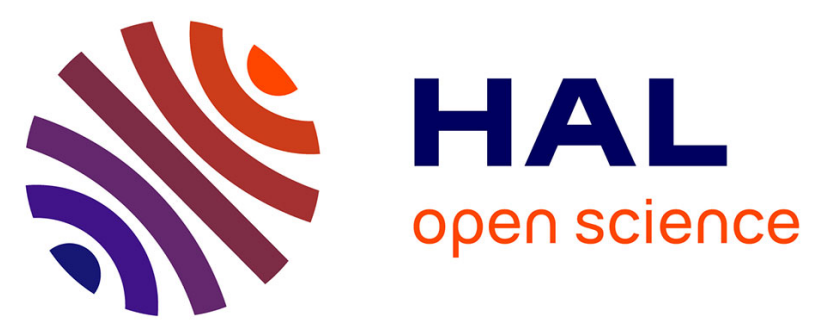

\title{
Biocompatible Polyion Complex Micelles Synthesized from Arborescent Polymers
}

Vo Thu An Nguyen, Marie-Claire de Pauw-Gillet, Olivier Sandre, Mario Gauthier

\section{- To cite this version:}

Vo Thu An Nguyen, Marie-Claire de Pauw-Gillet, Olivier Sandre, Mario Gauthier. Biocompatible Polyion Complex Micelles Synthesized from Arborescent Polymers. Langmuir, 2016, 32 (50), pp.1348213492. 10.1021/acs.langmuir.6b03683 . hal-01404628v2

\section{HAL Id: hal-01404628 \\ https://hal.science/hal-01404628v2}

Submitted on 4 Mar 2017

HAL is a multi-disciplinary open access archive for the deposit and dissemination of scientific research documents, whether they are published or not. The documents may come from teaching and research institutions in France or abroad, or from public or private research centers.
L'archive ouverte pluridisciplinaire HAL, est destinée au dépôt et à la diffusion de documents scientifiques de niveau recherche, publiés ou non, émanant des établissements d'enseignement et de recherche français ou étrangers, des laboratoires publics ou privés.

\section{(ㅇ)(1) $\$$}

Distributed under a Creative Commons Attribution - NonCommercial - NoDerivatives| 4.0 
This document is the Accepted Manuscript version of a Published Work that appeared in final form in Langmuir, 2016, 32(50), 13482-13492, after peer review and technical editing by the publisher. Copyright @ American Chemical Society. To access the final edited and published work see http://pubs.acs.org/doi/abs/10.1021/acs.langmuir.6b03683

\section{Biocompatible Polyion Complex Micelles Synthesized from Arborescent Polymers \\ Vo Thu An Nguyen, ${ }^{+, \neq,}{ }_{8}$ Marie-Claire De Pauw-Gillet, ${ }^{\S}$ Olivier Sandre, ${ }^{*}+, \neq$ and Mario Gauthier ${ }^{*} 8$ \\ ${ }^{\dagger}$ Univ. Bordeaux, LCPO, UMR 5629, F-3360o Pessac, France \\ ${ }^{\ddagger}$ CNRS, Laboratoire de Chimie des Polymères Organiques, UMR 5629, F-336oo Pessac, France \\ ${ }^{\S}$ Mammalian Cell Culture Laboratory, GIGA-R, Université de Liège, B-40oo Liège, Belgium \\ sDepartment of Chemistry, University of Waterloo, Waterloo, ON N2L 3 G1, Canada}

KEYWORDS: Polyion Complex Micelle, Arborescent Polymer, Double-Hydrophilic Block Copolymer, ATRP, Core-Shell Structure, Cytotoxicity, Cell Internalization

ABSTRACT: Water-dispersible polyion complex (PIC) micelles were prepared by the self-assembly of an arborescent polystyrene-graft-poly(2-vinylpyridine) copolymer (denoted GoPS- $g$-P2 $\mathrm{VP}$ or $\mathrm{G} 1$ ) serving as core and a poly(acrylic acid)-block-poly(2hydroxyethyl acrylate) (PAA-b-PHEA) doublehydrophilic block copolymer (DHBC) forming a shell. Varying the density of hydrophilic polymer chains in the stabilizing layer provided control over the size and structure of the entities obtained, from large flocculated species to stable isolated PIC micelles with diameters ranging from 42 to $67 \mathrm{~nm}$. The hydrodynamic radius (determined from dynamic light scattering measurements), and the weight-average

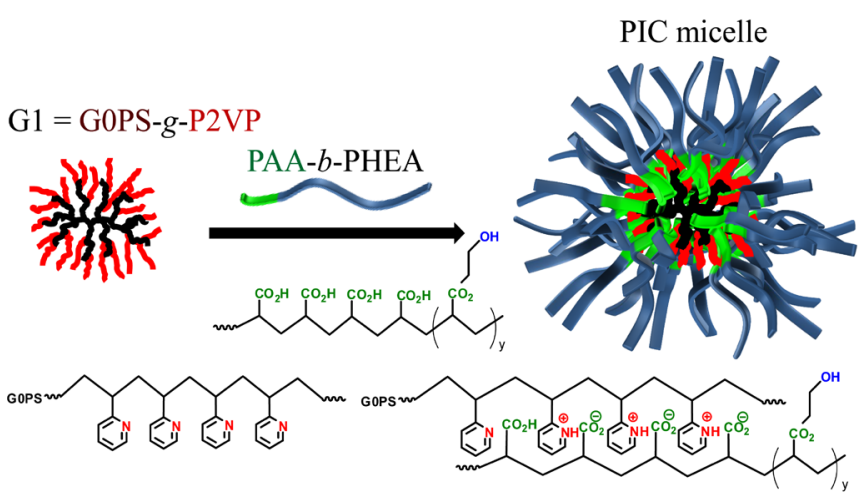
molar mass $\left(M_{\mathrm{w}}\right)$ and radius of gyration of the scatterers (extracted from static multi-angle light scattering data) evidenced the formation of either isolated or aggregated PIC micelles depending on the self-assembly conditions used $(\mathrm{pH}$, concentration and mixing molar ratio $f)$. Changes in the morphology of the arborescent copolymer after complexation were observed by atomic force microscopy (AFM) imaging. In particular, by varying the force applied with the AFM tip on the samples, the core-shell structure of the PIC micelles was clearly evidenced. The PIC micelles displayed no significant cytotoxicity towards mouse fibroblast L929 cells, a standard cell line recommended for toxicity assays, due to the good biocompatibility of the hydrophilic PAA-b-PHEA shell. In spite of a negative residual zeta potential due to an excess of negative charges, fluorescently labeled PIC* micelles were successful internalized by L929 cells, as confirmed by laser scanning confocal microscopy (LSCM) and transmission electron microscopy (TEM).

\section{INTRODUCTION}

In biomedical applications, colloidal stability is of critical importance to ensure the safety and efficacy of nanoscale products, ${ }^{1}$ since long blood circulation times are needed both for contrast agents and nanomedicines, while particles larger than $5 \mu \mathrm{m}$ can cause capillary blockage and embolism. ${ }^{2}$ The modification of the surface of nanoparticles (NPs) by self-assembly or complexation with a copolymer is a technique commonly applied to the delivery of DNA (gene therapy) and oligonucleotides (anti-sense therapy), ${ }^{3}$ dendrimer porphyrin photosensitizers (photodynamic therapy), ${ }^{4}$ drugs $^{5}$ and other types of hydrophobic nanomaterials, ${ }^{6}$ by protecting (shielding) specific functions within the micellar core. Van der Waals (VDW) interactions are considered the main driving force leading to particle dispersion instability. However these can be counterbalanced by steric repulsions arising from a polymer coating, for example through adsorbed or grafted chains. ${ }^{7-8}$ When the magnitude of the attraction force between two colloidal particles at contact is greater than the thermal energy $\left(k_{\mathrm{B}} T\right)$ flocculation occurs, as seen for large cores stabilized by a low $M_{\mathrm{w}}$ polymer. ${ }^{7}$ Increasing the $\overline{M_{\mathrm{w}}}$ of the stabilizing polymer efficiently reduces the magnitude of the VDW forces by limiting the minimal approach distance between the particles. Qualitatively, the polymer layer thickness must exceed the VDW effective attraction distance of 5 $\mathrm{nm}$ to impart stability to the dispersed phase. ${ }^{7}$ Since electrostatic stabilization is very sensitive to the ionic strength and the dielectric constant of the dispersion medium, polymeric stabilization (also referred to as steric stabilization), or a combination of steric and electrostatic (electrosteric) stabilization were preferred in this work, because the objective was to disperse the micelles in cell culture media. Considering that the grafted $\mathrm{P}_{2} \mathrm{VP}$ units of the arborescent $\mathrm{G}_{1}$ or GoPS- $g$ $\mathrm{P}_{2} \mathrm{VP}$ copolymer used in this investigation can be protonated, a polymer stabilizing shell bound through polyionic interactions appears promising, since it offers stronger interactions than physical adsorption and is much more versatile than covalent bonding. 
This document is the Accepted Manuscript version of a Published Work that appeared in final form in Langmuir, 2016, 32(50), 13482-13492, after peer review and technical editing by the publisher. Copyright (C) American Chemical Society. To access the final edited and published work see http://pubs.acs.org/doi/abs/10.1021/acs.langmuir.6b03683

The use of electrostatic interactions between two linear and oppositely charged polymers to form PIC micelles was first reported in the mid-1990s and immediately drew considerable attention. ${ }^{9-11}$ The main driving force for polyion complexation is a combination of Coulombic attraction and an entropy gain through the release of counterions. ${ }^{9-11}$ More precisely, polyion complex formation is ascribed to a decrease in total electrostatic free energy, due to a change in translational entropy for the small counterions and to the total electrostatic (or Born) energy. ${ }^{12}$ Hydrophobic interactions and hydrogen bonding are considered additional contributions to the polyion complex formation process.

Hydrogen bonding was sometimes cited as the driving force for the complexation of poly(2-vinylpyridine) ( $\left.\mathrm{P}_{2} \mathrm{VP}\right)$ or poly(4-vinylpyridine) $\left(\mathrm{P}_{4} \mathrm{VP}\right)$ homopolymers with poly(acrylic acid) (PAA) or poly(methacrylic acid) (PMAA) in ethanol/water (1:1) solutions. ${ }^{13}$ Intermolecular hydrogen bonding was also mentioned in the complexation of $\mathrm{P}_{4} \mathrm{VP} / \mathrm{P}_{2} \mathrm{VP}$-containing block copolymers (BCs) with $\mathrm{PAA}$ in $\mathrm{DMF},{ }^{14}$ with preformed PS- $b$-PAA micelles in ethanol, ${ }^{15}$ as well as with triblock copolymers of poly(ethylene oxide) monomethyl ether methacrylate and acrylic acid, $\left(\mathrm{PEO}_{11} \mathrm{MA}\right)_{63}-b-\mathrm{PAA}_{657}-b-$ $\left(\mathrm{PEO}_{11} \mathrm{MA}\right)_{63}$ in DMF. ${ }^{16}$ By changing the solvent, tuning the chain length and adjusting the stoichiometry ratio of the complex, the extent of hydrogen bonding between PAA and poly(3-caprolactone)-block-poly(2-vinyl pyridine) in THF/ethanol could be controlled. ${ }^{17}$ The solvent was found to have a strong impact on the nature of the driving force for the complexation between $\mathrm{P}_{4} \mathrm{VP}$ and PS- $b$-PAA: Weak hydrogen bonding was observed in ethanol, while strong polyionic interactions were reported in ethanol/water (1:1) solutions. ${ }^{18}$

Polyion complexation in an aqueous environment is not straightforward for the weak base $\mathrm{P}_{2} \mathrm{VP}$, since the $\mathrm{pH}$ affects the degree of ionization of weak polyelectrolytes before complexation. $^{19}$ Thus PIC micelles obtained by the complexation of $\mathrm{P}_{2} \mathrm{VP}-b-\mathrm{PEO}$ with the strong polyanion sodium poly $\left(4^{-}\right.$ styrenesulfonate) in water acidified to $\mathrm{pH} 5$ exhibited reversible dissociation at elevated $\mathrm{pH}$ and reassembly upon decreasing the $\mathrm{pH}^{20}{ }^{20}$ The formation of PIC micelles upon mixing protonated P2VP- $b$-PEO with PMAA- $b$ PEO could only be achieved within a limited $\mathrm{pH}$ range (2 $<\mathrm{pH}<6.1$ ) to avoid the self-assembly into pure (single polymer) micelles of either PMAA- $b$-PEO at low $\mathrm{pH}$ or

\section{EXPERIMENTAL SECTION}

Synthesis of polymers. The $\mathrm{G}_{1}$ or GoPS- $g$ - $\mathrm{P}_{2} \mathrm{VP}$ copolymer $\left(\overline{M_{\mathrm{n}}}=1.1 \times 10^{6} \mathrm{~g} \cdot \mathrm{mol}^{-1} ; \overline{M_{\mathrm{w}}} / \overline{M_{\mathrm{n}}}=1.08\right)$, consisting in a Go or comb-branched polystyrene substrate grafted with $182 \mathrm{P} 2 \mathrm{VP}$ side-chains and having a $2 \mathrm{VP}$ unit content of $91 \mathrm{~mol} \%$, was synthesized by Gauthier and Munam..$^{31}$ The synthesis and characterization of PAA- $b$-PHEA DHBCs with varying block lengths are described in the Electronic Supporting Information (ESI) S1. The
$\mathrm{P}_{2} \mathrm{VP}-b$-PEO at high $\mathrm{pH}^{21}$ Interesting phase behavior and micellization phenomena (e.g. heteroarm star-like micelles, irregular aggregates...) were also observed at various $\mathrm{pH}$ in the self-complexation of a P2VP- $b$-PMMA$b$-PAA block terpolymer in aqueous dilute solutions. ${ }^{22}$ Wang et al. ${ }^{23}$ further reported the penetration of poly $(N-$ isopropylacrylamide-co-4-vinylpyridine) statistical copolymer chains dissolved in an $\mathrm{HCl}$ solution into rigid preformed core-shell PS-co-PMAA microspheres.

To the best of our knowledge, most of the studies in the literature were performed with polyvinylpyridine (PVP) homopolymers or block copolymers, but not with complex polymer architectures containing PVP blocks as side-chains. Therefore this is the first report on the complexation of poly(acrylic acid)- $b$-poly(2hydroxyethyl acrylate) (PAA- $b$-PHEA) with an arborescent graft copolymer (GoPS- $g$-P2 VP) in water to produce well-defined (non-aggregated) PIC micellar species. ${ }^{24-28}$ Water was used as the complexation solvent to obtain PIC micelles in one step, instead of relying upon micellization in organic solvents followed by transfer to aqueous media by heating or stepwise dialysis. ${ }^{18,22}$ The current investigation aimed to characterize the PIC micelles in their dispersed form before examining their structure in the dry state, in contrast to most studies mentioned above. The goal of the PIC process was to anchor PAA- $b$-PHEA onto the surface of the $\mathrm{G} 1$ copolymer, such that the PHEA tails would form a swollen shell increasing the separation distance between the particles to the extent that VDW attractions would become negligible $(>5 \mathrm{~nm}$, as observed for many colloidal systems). ${ }^{7}$ The micellar structures thus obtained were expected to be colloidally stable in water at $\mathrm{pH} 7$, and most importantly biocompatible due to the shell of PHEA, a highly biocompatible material. ${ }^{29-30}$ The ability of PAA- $b$-PHEA DHBCs (with different block lengths) to stabilize the hydrophobic Gi substrate was evaluated using dynamic light scattering (DLS) and static multi-angle laser light scattering (MALLS) measurements, while the PIC micelle internal structure was further analyzed by atomic force microscopy (AFM). Cytotoxicity and cell internalization studies are presented in the last section, to demonstrate the usefulness of such PIC micelles in a biological context.

preparation of fluorescently labeled $\mathrm{PAA}_{27}-b-\mathrm{PHEA}_{260}$ (referred to as $\mathrm{PAA}_{27}{ }^{*}-b$-PHEA ${ }_{260}$ ) is also described in ESI S2.

Preparation of Polyion Complex Micelles. Complexation of the $\mathrm{G} 1$ arborescent copolymer with various amounts of different PAA- $b$-PHEA DHBCs was carried out in aqueous solutions. Hereafter the parameter $f=\mathrm{CO}_{2} \mathrm{H} / \mathrm{N}$ will be used to quantify the molar ratio between the $\mathrm{CO}_{2} \mathrm{H}$ groups (from the PAA segment of the DHBCs) and the $\mathrm{N}$ moieties (2VP units of $\mathrm{G} 1$ ). The 
This document is the Accepted Manuscript version of a Published Work that appeared in final form in Langmuir, 2016, 32(50), 13482-13492, after peer review and technical editing by the publisher. Copyright (C) American Chemical Society. To access the final edited and published work see http://pubs.acs.org/doi/abs/10.1021/acs.langmuir.6b03683

following procedure describes the complexation of $\mathrm{G} 1$ with $\mathrm{PAA}_{27}-b-\mathrm{PHEA}_{260}$ for $f=0.5$. In a $10-\mathrm{mL}$ vial, G1 $(1.7$ $\mathrm{mg}, 14.7 \mu \mathrm{mol}$ of $\mathrm{N}$ ) was completely dissolved in $300 \mu \mathrm{L}$ of aqueous $\mathrm{HCl}$ solution at $\mathrm{pH} 1.4$ by sonication $(37 \mathrm{kHz}$, 30 min, Elmasonic ${ }^{\mathrm{TM}}$ Ultrasonic Cleaner SHo75EL). A pH 7 aqueous solution of $\mathrm{PAA}_{27}-b-\mathrm{PHEA}_{260}(8.5 \mathrm{mg}, 5$ $\mathrm{mg} \cdot \mathrm{mL}^{-1}, 7.35 \mu \mathrm{mol}$ of $\left.\mathrm{CO}_{2} \mathrm{H}\right)$ was quickly added. The mixture was stirred on a magnetic stirrer for $1 \mathrm{~h}$ before the $\mathrm{pH}$ was adjusted to 4.7 with a $1 \mathrm{M} \mathrm{NaOH}$ solution, and stirring was continued for $1 \mathrm{~h}$. The $\mathrm{pH}$ was further adjusted to 7 with $0.1 \mathrm{M} \mathrm{NaOH}$ and the solution was stirred for $30 \mathrm{~min}$. The solution was then dialyzed (50,00o MWCO Spectra/Por 7 regenerated cellulose bag) against Milli-Q water $(5 \mathrm{~L})$ for $24 \mathrm{~h}$ before it was collected and stored at $4{ }^{\circ} \mathrm{C}$. The preparation of the fluorescently labeled PIC micelles (hereinafter referred to as $\mathrm{PIC}^{*}$ micelles) was performed in the dark by the same procedure, but with a mixture of $5 \% \mathrm{PAA}_{27}{ }^{*}-b$ PHEA $_{260}$ (7.0\% labeled) and $95 \mathrm{~mol} \%$ of (non-labeled) $\mathrm{PAA}_{27}-b-\mathrm{PHEA}_{260}$. Characterization of the PIC micelles by DLS, MALLS and AFM is described in ESI S3.

Biocompatibility Assessment. The materials used for the cytotoxicity and cell internalization investigations of PIC micelles in L929 cells are described in ESI S4. These murine fibroblasts are recommended in the ISO10993-1: 2009 procedure "Biological evaluation of medical devices".

\section{RESULTS AND DISCUSSION}

Synthesis of the PAA-b-PHEA DHBCs and Fluorescent Labeling. The determination of the number-average degree of polymerization of the polymers is described in ESI S1.2. The apparent molar mass dispersity of copolymers $\emptyset_{\mathrm{SEC}}=M_{\mathrm{w}} \cdot \bar{M}_{\mathrm{n}}^{-1}$, determined by size-exclusion chromatography (ESI S1.2), was as follows: $\mathrm{PAA}_{13}-b$ - $\mathrm{PHEA}_{50}\left(\bigoplus_{\mathrm{SEC}}=1.15\right), \mathrm{PAA}_{13}-b-$ PHEA $_{150}\left(\bigoplus_{\mathrm{SEC}}=1.23\right), \mathrm{PAA}_{27}-b-\mathrm{PHEA}_{56}\left(\bigoplus_{\mathrm{SEC}}=1.08\right)$, $\mathrm{PAA}_{27}-b-\mathrm{PHEA}_{260} \quad\left(\bigoplus_{\mathrm{SEC}}=1.16\right)$. The number of fluoresceinamine (FA) molecules conjugated per $\mathrm{PAA}^{*}{ }_{27}{ }^{-}$ $b$-PHEA ${ }_{260}$ molecule (containing $27 \mathrm{CO}_{2} \mathrm{H}$ groups) was $1.88 \pm 0.15$, corresponding to $7.0 \mathrm{~mol} \%$ labeling, which was sufficient to image the micelles in fluorescence microscopy whilst not changing their colloidal properties (hydrodynamic diameter and zeta potential; ESI S2.2).

PIC Micelles in Water. GoPS- $g$-P2VP is insoluble in aqueous media at neutral $\mathrm{pH}$, while PAA- $b$-PHEA is soluble. No micelles nor aggregates are formed when mixing them directly at $\mathrm{pH}$ 7. To maximize the interactions between the two weak polyelectrolytes PAA and $\mathrm{P}_{2} \mathrm{VP}$, it is crucial to ionize these components before the complexation, ${ }^{19}$ by protonating a portion of the amine groups of $\mathrm{P}_{2} \mathrm{VP}\left(\mathrm{pK}_{\mathrm{a}}=5\right)^{19}$ into $\mathrm{NH}^{+}$, and ionizing some of the $\mathrm{CO}_{2} \mathrm{H}$ moieties of PAA $\left(\mathrm{p} K_{\mathrm{a}}=6.5\right)^{32}$ into $\mathrm{CO}_{2}^{-}$. It should be easier to form stable electrostatic bonds between polycations and polyanions within a $\mathrm{pH}$ range where a majority of both the acid and basic moieties exist in their ionic forms, ${ }^{19}$ but this was difficult to achieve for our system. Figure SI-5 illustrates the challenge in finding a $\mathrm{pH}$ range where the majority of both components exist in their ionic forms. Complexation is unfavorable at either too low (acidic) or too high (basic) $\mathrm{pH}$ values, but $\mathrm{pH} 4.7$ was selected as a compromise solution such that ca. $67 \%$ of the $2 \mathrm{VP}$ moieties would be protonated, while $1.6 \%$ of the carboxylic groups would exist in their anionic form according to the classical Henderson-Hasselbalch law of ionization for weak acids and bases. The interactions between PAA and P2VP may be much stronger at that $\mathrm{pH}$ in practice, since the apparent $\mathrm{p} K_{\mathrm{a}}$ value of PAA was found by Burke and Barrett ${ }^{33}$ to shift downwards by up to $4 \mathrm{pH}$ units when incorporated into multilayer assemblies, which would result in larger acid and base activities.

Intermolecular hydrogen bonding between neutral $\mathrm{H}$ donor $\mathrm{CO}_{2} \mathrm{H}$ groups in the PAA segments and neutral $\mathrm{H}$ acceptor $\mathrm{N}$ groups in $\mathrm{P}_{2} \mathrm{VP}$ has been claimed to be the main driving force for complexations performed in organic solvents. ${ }^{14,17,34-35}$ In aqueous environments at $\mathrm{pH}$ 4.7, multiple intermolecular hydrogen bonding interactions may also assist at least transiently the electrostatic interactions in the complexation process. However at $\mathrm{pH}$, these hydrogen bonds should be perturbed due to increased ionization of the $\mathrm{CO}_{2} \mathrm{H}$ groups, allowing the electrostatic interactions to play a dominant role in the polyion complexation process. ${ }^{36}$ At $\mathrm{pH} 7 \mathrm{ca} .76 \%$ of the $\mathrm{CO}_{2} \mathrm{H}$ functionalities should exist in their ionic form, while much less (i.e. $<1 \%$ ) of the $\mathrm{N}$ moieties may stay protonated, which should result in negatively charged PIC micelles at every $f$ investigated. This was confirmed with zeta potential measurements (Figure 1). Electrostatic repulsions between these negatively charged PIC micelles, as indicated by their large zeta potential (ZP) values (Figure 1), may contribute significantly to colloidal stability of the particles, in addition to steric stabilization by the neutral PHEA chains.

Dynamic Light Scattering (DLS) Measurements. The PIC process was optimized in terms of its ability to yield exclusively isolated (non-aggregated) micellar structures, i.e. incorporating only one $\mathrm{Gl}$ substrate molecule within their core. To this end, DLS measurements at $90^{\circ}$ were used to generate numberand intensity-weighted size distributions and the corresponding average hydrodynamic diameters for most sample compositions investigated. The G1 substrate had an intensity-average hydrodynamic diameter $D_{\mathrm{h}}^{\mathrm{I}}=29 \pm 4 \mathrm{~nm}$, with an extremely low polydispersity index $(\mathrm{PDI}=0.04)$ at $\mathrm{pH}$, which is much larger than the theoretical hard-core diameter $\left(D_{\mathrm{G} 1}=\right.$ $14.6 \mathrm{~nm}$ calculated from the bulk densities of PS and $\mathrm{P}_{2} \mathrm{VP}$ of 1.05 and $1.17 \mathrm{~g} / \mathrm{cm},{ }^{3,37}$ respectively, and the molar mass of the $\mathrm{G}_{1}$ polymer) for a collapsed $\mathrm{PS}_{-} \mathrm{P}_{2} \mathrm{VP}$ hydrophobic sphere at $\mathrm{pH}$ 7. The coiled dimensions of the PHEA segments $\left(l_{\text {PHEA }}\right)$ in the different DHBCs, ranging from 7.1 to $12.2 \mathrm{~nm}$, suggests that the absolute 
This document is the Accepted Manuscript version of a Published Work that appeared in final form in Langmuir, 2016, 32(50), 13482-13492, after peer review and technical editing by the publisher. Copyright @ American Chemical Society. To access the final edited and published work see http://pubs.acs.org/doi/abs/10.1021/acs.langmuir.6b03683

maximum hydrodynamic diameter of isolated PIC micelles (derived from a single G1 molecule), denoted thereafter $D_{\max }$, should be in a range of ca. $29-40 \mathrm{~nm}$, with a narrow and unimodal size distribution, in analogy to the Gi substrate. The thickness of the protecting layer $\delta^{\mathrm{n}}=\frac{1}{2}\left[D_{\mathrm{h}(\mathrm{PIC})}^{\mathrm{n}}-D_{G 1}\right]$ can be calculated for an isolated micelle, where $D_{\mathrm{G} 1} \approx 14.6 \mathrm{~nm}$ for a collapsed spherical PS$g$-P2VP core. This information was used to determine the nature of the core-shell nanoparticles obtained, i.e. whether they were built around a single Gi polymer core (isolated micelles) or aggregated (multi-core) species.

In all cases where an intensity-weighted unimodal size distribution was obtained by DLS analysis, similar results were also obtained for number- and volumeweighted distribution curves, but with peaks in a lower size range (Figures SI-6 and SI-7). The intensity- weighted z-average $D_{\mathrm{h}}^{\mathrm{I}}$ was obtained by cumulants analysis of the autocorrelation function for the scattered intensity (see ESI S3.1). This value is shifted towards larger sizes as compared to the number-average radius $D_{\mathrm{h}}^{\mathrm{n}}$, because it is dominated by the larger components of the size distribution. ${ }^{38-39}$ Since only unimodal distributions were obtained in the current investigation, the use of cumulants analysis was justified and the number-weighted mean diameter $D_{\mathrm{h}}^{\mathrm{n}}$ can be used to describe the size of the PICs without bias towards larger sizes. The $D_{\mathrm{h}}^{\mathrm{n}}$ values obtained, reported together with the $D_{\mathrm{h}}^{\mathrm{I}}$ values in Table 1 , therefore provide more realistic PIC dimensions than the z-average $D_{\mathrm{h}}^{\mathrm{I}}$ for comparison with other number-weighted measurements (e.g. AFM analysis).

Table 1. Hydrodynamic diameter and polydispersity index of G1@PAA-b-PHEA PIC micelles in water at $90^{\circ}, \mathrm{pH} 7$ and 25 ${ }^{\circ} \mathrm{C}$ for various $f$ ratios. The optimal $f$ values for each DHBC are bolded.

\begin{tabular}{|c|c|c|c|c|c|c|c|c|}
\hline & $f$ & 9 & 6 & 3 & 1 & 0.5 & 0.25 & 0.125 \\
\hline \multirow{3}{*}{$\begin{array}{c}\mathrm{G1} @ \mathrm{PAA}_{27}-b- \\
\mathrm{PHEA}_{56} \\
\left(l_{\mathrm{PHEA}} \approx 7 \cdot 3 \mathrm{~nm},\right. \\
\left.D_{\max } \approx 29 \mathrm{~nm}\right)\end{array}$} & $D_{\mathrm{h}}^{\mathrm{I}} / D_{\mathrm{h}}^{\mathrm{n}}(\mathrm{nm})^{\mathrm{a}}$ & $67 / 44$ & $84 / 61$ & $184 / 80$ & 1600 & - & - & - \\
\hline & $\mathrm{PDI}^{\mathrm{b}}$ & 0.16 & 0.10 & 0.20 & $\sim 1$ & - & - & - \\
\hline & $\delta^{\mathrm{n}}(\mathrm{nm})^{\mathrm{c}}$ & 15 & - & - & - & - & - & - \\
\hline \multirow{3}{*}{ 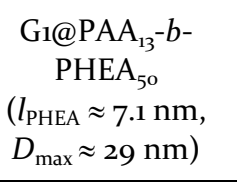 } & $D_{\mathrm{h}}^{\mathrm{I}} / D_{\mathrm{h}}^{\mathrm{n}}(\mathrm{nm})$ & $48 / 36$ & $66 / 45$ & $100 / 75$ & 1290 & - & - & - \\
\hline & PDI & 0.07 & 0.10 & 0.07 & $\sim 1$ & - & - & - \\
\hline & $\delta^{\mathrm{n}}(\mathrm{nm})$ & 11 & - & - & - & - & - & - \\
\hline \multirow{3}{*}{$\begin{array}{c}\mathrm{G}_{1} @ \mathrm{PAA}_{13}-b- \\
\mathrm{PHEA}_{150} \\
\left(l_{\mathrm{PHEA}} \approx 10.1 \mathrm{~nm}\right. \\
\left.D_{\max } \approx 35 \mathrm{~nm}\right)\end{array}$} & $D_{\mathrm{h}}^{\mathrm{I}} / D_{\mathrm{h}}^{\mathrm{n}}(\mathrm{nm})$ & - & - & $50 / 32$ & $46 / 29$ & $104 / 83$ & $169 / 98$ & 660 \\
\hline & PDI & - & - & 0.18 & 0.14 & 0.04 & 0.16 & 0.47 \\
\hline & $\delta^{\mathrm{n}}(\mathrm{nm})$ & - & - & 9 & 7 & - & - & - \\
\hline \multirow{3}{*}{$\begin{array}{c}\mathrm{G}_{1} @ \mathrm{PAA}_{27}-b- \\
\mathrm{PHEA}_{260} \\
\left(l_{\mathrm{PHEA}} \approx 12.2 \mathrm{~nm},\right. \\
\left.D_{\max } \approx 39 \mathrm{~nm}\right)\end{array}$} & $D_{\mathrm{h}}^{\mathrm{I}} / D_{\mathrm{h}}^{\mathrm{n}}(\mathrm{nm})$ & - & - & $63 / 37$ & $51 / 34$ & $42 / 26$ & $87 / 53$ & 642 \\
\hline & PDI & - & - & 0.18 & 0.13 & 0.08 & 0.18 & 0.44 \\
\hline & $\delta^{\mathrm{n}}(\mathrm{nm})$ & - & - & 11 & 10 & 6 & - & - \\
\hline
\end{tabular}

${ }^{\mathrm{a}} D_{\mathrm{h}}^{\mathrm{I}}$ and $D_{\mathrm{h}}^{\mathrm{n}}$ : intensity-weighted and number-weighted hydrodynamic diameters; ${ }^{\mathrm{b}}$ Polydispersity index; ${ }^{\mathrm{c}}$ Thickness of protecting layer $\delta^{\mathrm{n}}=\frac{1}{2}\left[D_{\mathrm{h}(\mathrm{PIC})}^{\mathrm{n}}-D_{G 1}\right]$ calculated for an isolated micelle, where $D_{\mathrm{G} 1} \approx 14.6 \mathrm{~nm}$ for a collapsed spherical PS$g$-P2VP core. The coiled dimensions of PHEA blocks indicated in parentheses $\left(l_{\text {PHEA }}\right)$ were used to estimate the maximum theoretical diameter of an isolated core-shell assembly for each copolymer.

G1@PAA $27-$-b-PHEA 56 and G1@PAA 13 -b-PHEA ${ }_{50}\left(l_{\text {PHEA }}\right.$ $\left.\approx 7.1-7.3 \mathrm{~nm}, D_{\max } \approx 29 \mathrm{~nm}\right)$. These two systems had similar characteristics and thus will be discussed concomitantly. The $f=1$ ratio failed to yield a denseenough polymeric shell to stabilize the G1 molecules, resulting in $>1.2 \mu \mathrm{m}$ diameter agglomerates. For $f=3,6$ and 9, stable PIC micelle dispersions were obtained with decreased $D_{\mathrm{h}}^{\mathrm{n}}$ values approaching the theoretical $D_{\max }$. Increasing the $f$ ratio provided more DHBC chains to the stabilizing shell and increased the $\mathrm{CO}_{2}{ }^{-}$charge density surrounding the $\mathrm{G} 1$ molecules, leading to stronger electrosteric repulsions, as well as smaller and more stable particles due to their enhanced colloidal stability. The reduction in the PAA chain length from 27 to 13 units, whilst maintaining a comparable length for the PHEA block, resulted in smaller particle sizes and much narrower size distributions (for $f=3,6,9$ ). Indeed when $\mathrm{PAA}_{27}-b$-PHEA 56 and $\mathrm{PAA}_{13}-b$-PHEA 50 are used at the same $f$ ratio, the latter corresponds to twice as many chains (providing a higher density of stabilizing segments) for the same number of $\mathrm{CO}_{2} \mathrm{H}$ functionalities. However even for the highest ratio $(f=9)$, the micelles seem to be aggregated since: $i)$ the $D_{\mathrm{h}}^{\mathrm{n}}=44-36 \mathrm{~nm}$ is much larger than $D_{\max } \approx 29 \mathrm{~nm}$; ii) the thickness $\delta^{\mathrm{n}} \approx 11^{-}$ 
This document is the Accepted Manuscript version of a Published Work that appeared in final form in Langmuir, 2016, 32(50), 13482-13492, after peer review and technical editing by the publisher. Copyright (C) American Chemical Society. To access the final edited and published work see http://pubs.acs.org/doi/abs/10.1021/acs.langmuir.6b03683

$11 \mathrm{~nm}$ is larger than $l_{\mathrm{PHEA}} \approx 7 \cdot 3-7.1 \mathrm{~nm}$. The very negative $\mathrm{ZP}$ of the PIC micelles (ca. $-29 \mathrm{mV}$, Figure 1) also confirms the excess of $\mathrm{CO}_{2}^{-}$at $\mathrm{pH} 7$ in all cases, and suggests an important contribution of electrostatic repulsions to PIC micelle stability. In most cases, however, even a combination of electrostatic and steric stabilization was insufficient to produce isolated PIC micelles. The optimal composition of these systems was determined to be for $f=9$, which is relatively high.
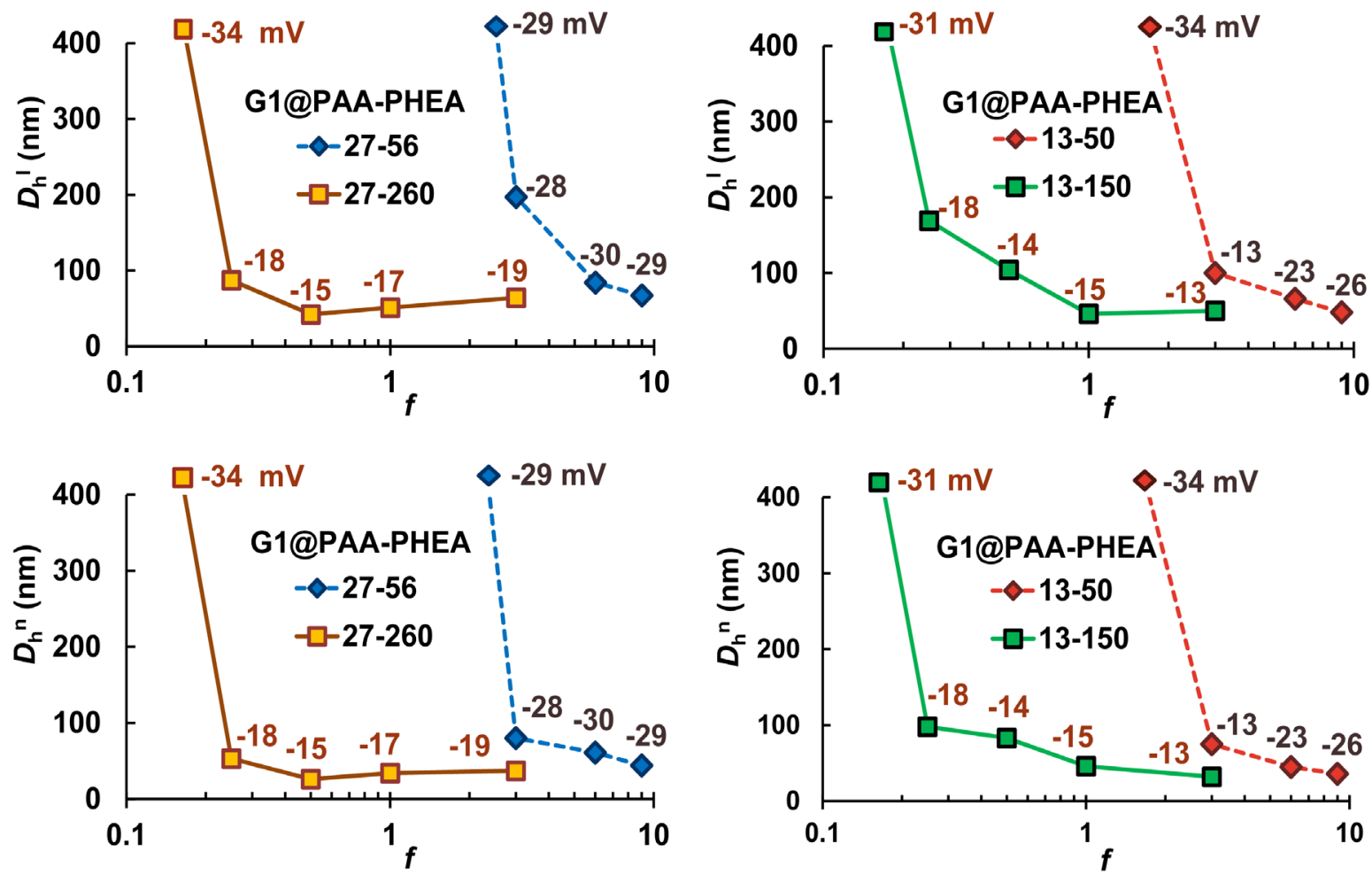

Figure 1. Intensity- (top) and number-weighted hydrodynamic diameters (bottom) for four series of PIC micelles. The first data point in each series is disconnected from the trend line because it is off-scale. The zeta potential values for the samples are provided next to each data point.

G1@PAA 13 -b-PHEA 150 ( $\left.l_{\text {PHEA }} \approx 10.1 \mathrm{~nm}, D_{\max } \approx 35 \mathrm{~nm}\right)$ and G1@PAA $\mathbf{2 7}_{\mathbf{2 7}}$-b-PHEA $\mathbf{2 6 o}_{\mathbf{2}}\left(l_{\mathrm{PHEA}} \approx \mathbf{1 2 . 2} \mathrm{nm}, D_{\max } \approx 39\right.$ $\mathrm{nm})$. Good stabilization was observed for a ratio $f=3$, yielding PIC micelles with $D_{\mathrm{h}}^{\mathrm{n}}=32 \mathrm{~nm}$ and $37 \mathrm{~nm}(<$ $\left.D_{\text {max }}\right)$, respectively, and relatively narrow size distributions (PDI $=0.18)$. The seemingly nonaggregated nature of these micelles highlights the advantages of these DHBCs. The thicker PHEA shell (shell thickness $\delta^{\mathrm{n}} \approx 9$ and $11 \mathrm{~nm}$, exceeding the $5 \mathrm{~nm}$ effective distance of VDW forces) provides enhanced steric stability for the PIC micelles, which favors the formation of isolated PIC species even though the contribution from electrostatic stabilization is fairly small ( $\mathrm{ZP}=-13$ and $-19 \mathrm{mV}$, Figure 1$)$.

Stabilization was also investigated for $f=1$, yielding G1@PAA PA-PHEA $_{150}$ PIC micelles with $D_{\mathrm{h}}^{\mathrm{n}}=29 \mathrm{~nm}(\mathrm{PDI}$ $=0.14, \mathrm{ZP}=-15 \mathrm{mV})$, and for G1@PAA ${ }_{27}-\mathrm{b}-\mathrm{PHEA}_{260} D_{\mathrm{h}}^{\mathrm{n}}=$ $34 \mathrm{~nm}(\mathrm{PDI}=0.13, \mathrm{ZP}=-17 \mathrm{mV})$. These PIC micelles are still likely non-aggregated, with a shell thickness $\delta^{\mathrm{n}} \approx 7^{-}$ $10 \mathrm{~nm}$; for the same $f$ ratio, $\mathrm{PAA}_{27}-b-\mathrm{PHEA}_{260}$ increased the layer thickness by ca. $2-3 \mathrm{~nm}$, in agreement with the larger dimensions of the PHEA chains. Reducing the $f$ ratio from 3 to 1 decreased the density of DHBC in the micelles 3-fold, such that steric stabilization due to the long polymer chains presumably dominated colloidal stability. These results show that by introducing more HEA units into the polymeric stabilizer, the colloidal stability of the PIC micelles changed from electrosteric (a combination of electrostatic repulsion and steric stabilization, when using short PHEA chains) to predominantly steric stabilization (when employing longer PHEA blocks). Upon reducing the $f$ ratio further to $0.5,0.25$ and 0.125 , the decreased density of DHBC chains in the PIC assemblies led to flocculation for the $\mathrm{Gl} @ \mathrm{PAA}_{13}-\mathrm{b}-\mathrm{PHEA}_{150}$ system, suggesting that the optimal $f$ for this DHBC is $f=1$. The influence of steric stabilization imparted by longer chains is also evident as G1@PAA ${ }_{27}-b-\mathrm{PHEA}_{260} f=0.5$ had $D_{\mathrm{h}}^{\mathrm{n}}=26 \mathrm{~nm}$, fairly close to the size of the collapsed $\mathrm{G} 1$ core $\left(D_{\mathrm{G} 1}=14.6 \mathrm{~nm}, \delta^{\mathrm{n}} \approx 6\right.$ $\mathrm{nm}$ ) and a narrow size distribution (PDI $=0.08$ ), thus confirming their non-aggregated nature. The G1@PAA ${ }_{27}^{-}$ $b$-PHEA ${ }_{260} f=0.5$ PIC micelles are the smallest colloidally stable micelles obtained. The ca. $6 \mathrm{~nm}$ shell thickness gives a closest distance of approach between 
This document is the Accepted Manuscript version of a Published Work that appeared in final form in Langmuir, 2016, 32(50), 13482-13492, after peer review and technical editing by the publisher. Copyright (C) American Chemical Society. To access the final edited and published work see http://pubs.acs.org/doi/abs/10.1021/acs.langmuir.6b03683

two cores of $12 \mathrm{~nm}$, still exceeding the $5 \mathrm{~nm}$ minimum effective distance ${ }^{7}$ and further confirming the superior stabilizing ability of this copolymer. Further reduction in the $f$ ratio leads to fewer stabilizing chains per micelle. For $f=0.25$ and 0.125 , the DHBC content was insufficient for stabilization of the Gi copolymer in its isolated form, which led to the formation of larger, aggregated micellar species. The most efficient copolymer tested for the preparation of isolated PIC micelles was therefore $\mathrm{PAA}_{27}-b-\mathrm{PHEA}_{260}$, as it maintained a sufficient thickness for the protecting shell while allowing a sufficient density of chains to cover the G1 substrate. For these copolymers, the optimal $f$ was about $0.5^{-1}$, i.e. close to charge stoichiometry.

Multi-Angle Static and Dynamic Light Scattering. Static MALLS measurements were performed on selected PIC micelle samples over a concentration range of $0.2-1 \mathrm{mg} \cdot \mathrm{mL}^{-1}$ and at 25 angles ranging from $30-150^{\circ}$, to be extrapolated to zero concentration and angle by the Zimm technique (Figures SI-8 to SI-10) to determine their weight-average absolute molecular weight $\left(M_{\mathrm{w}}\right)$, radius of gyration $\left(R_{\mathrm{g}}\right)$, and second virial coefficient $\left(A_{2}\right)$.
The hydrodynamic radius $\left(R_{\mathrm{h}}\right)$ of these samples was also determined at 25 different angles by $2^{\text {nd }}$ order cumulants analysis of the dynamic light scattering (DLS) data at a concentration of $1 \mathrm{mg} \cdot \mathrm{mL}^{-1}$, and extrapolation to zero angle as discussed in ESI S3.3 (Fig. SI-11). The results obtained by both techniques are summarized in Table 2 .

Isolated vs. Aggregated Micelles. The nature of the PIC micelles may be investigated by comparing the experimental weight-average molecular weight $M_{\mathrm{w}(\operatorname{Exp})}$ obtained from static multi-angle laser light scattering (MALLS) data analysis with the molecular weight of the arborescent substrate $\left(M_{\mathrm{w}\left(\mathrm{G}_{1}\right)}=1.1 \times 10^{6} \mathrm{~g} \cdot \mathrm{mol}^{-1}\right)$ and the theoretical molecular weight based on the amounts of each component used in the complex formation, $M_{\mathrm{w}(\text { Theor })}=M_{\mathrm{w}\left(\mathrm{G}_{1}\right)} \times \mathrm{wt}_{(\mathrm{G} 1+\mathrm{BC})} / \mathrm{wt}_{(\mathrm{G} 1)}$ where $\mathrm{wt}_{(\mathrm{G} 1+\mathrm{BC})}$ is the total weight of PIC micelles recovered after dialysis. The formation of isolated micelles can be confirmed if $M_{\mathrm{w}(\mathrm{Exp})}$ is in a range comparable to $\overline{M_{\mathrm{w}}(\mathrm{G} 1)}$, while for $M_{\mathrm{w}(\mathrm{Exp})}>M_{\mathrm{w} \text { (Theor) }}$ the formation of aggregates is unambiguously demonstrated.

Table 2. Data derived from multi-angle static and dynamic light scattering measurements on PIC micelles. Italicized values indicate aggregated micelles due to insufficient coating and weak repulsion (low $A_{2}$ values).

\begin{tabular}{|c|c|c|c|c|c|c|c|c|c|}
\hline \multicolumn{2}{|c|}{$\mathbf{G}_{1} @ P A A_{x}-b-P H E A_{y}$} & \multicolumn{2}{|c|}{$M_{\mathrm{w}}\left(10^{6} \mathrm{~g} \cdot \mathrm{mol}^{-1}\right)$} & \multirow{2}{*}{$\begin{array}{l}\# \mathbf{B C} \\
/ \mathrm{PIC}\end{array}$} & \multirow{2}{*}{$\underset{(\mathbf{n m})}{R_{\mathrm{g}}}$} & \multirow{2}{*}{$R_{\mathrm{h}}(\mathrm{nm})$} & \multirow{2}{*}{ PDI } & \multirow{2}{*}{$\rho=R_{\mathrm{g}} / R_{\mathrm{h}}$} & \multirow{2}{*}{$\begin{array}{c}A_{2}\left(10^{-5} \mathrm{~cm}^{3}\right. \\
\left.\mathrm{mol} \cdot \mathrm{g}^{-2}\right)\end{array}$} \\
\hline & $f$ & Theor. & Exp. & & & & & & \\
\hline $27-56$ & 9 & 18.7 & 1.3 & 22 & 26.7 & 28.7 & 0.30 & 0.93 & 9.5 \\
\hline $13-50$ & 9 & 32.5 & 1.4 & 54 & $45 \cdot 3$ & 23 & 0.16 & 1.97 & 12.1 \\
\hline \multirow[t]{4}{*}{$13-150$} & 3 & 33.2 & 1.7 & 33 & 35.8 & 24.6 & 0.18 & 1.46 & 12.3 \\
\hline & 1 & 14.0 & 1.6 & 27 & $27 \cdot 7$ & $24 \cdot 5$ & 0.23 & 1.13 & 1.8 \\
\hline & 0.5 & 7.2 & 39 & - & 49.6 & $55 \cdot 5$ & 0.02 & 0.89 & 0.3 \\
\hline & 0.25 & $3 \cdot 5$ & 170 & - & 124 & 79.6 & 0.08 & 1.56 & 0.2 \\
\hline \multirow[t]{4}{*}{$27-260$} & 3 & 32.8 & 3.2 & 68 & 23.9 & 30 & 0.18 & 0.80 & 19.3 \\
\hline & 1 & 10.5 & 2.8 & 51 & 12.2 & 29.8 & 0.20 & 0.41 & 1.9 \\
\hline & 0.5 & 6.6 & 2.1 & 32 & $9 \cdot 9$ & 21.3 & 0.22 & 0.46 & $3 \cdot 3$ \\
\hline & 0.25 & 2.9 & 9.7 & - & 17.4 & 30.3 & 0.15 & 0.57 & 1.7 \\
\hline
\end{tabular}

The non-aggregated nature of PIC micelles prepared from the DHBC with long PHEA segments, G1@PAA $13-b-$ PHEA $_{150}$ with $f=3$ and 1 , and G1@PAA $27-b-$ PHEA $_{260}$ with $f$ $=0.5$ was previously concluded from the DLS measurements at $90^{\circ}$. This is also confirmed by the MALLS data since $\overline{M_{\mathrm{w}(\operatorname{Exp})}}<2 \times \overline{M_{\mathrm{w}(\mathrm{G} 1)}}$ with $\overline{M_{\mathrm{w}(\mathrm{G} 1)}}=1.1 \times 10^{6}$ $\mathrm{g} \cdot \mathrm{mol}^{-1}$. This is probably also true for $\mathrm{Gl@PAA} \mathrm{P}_{2}-b$ PHEA $_{260} f=3$ and $f=1$, for which $M_{\mathrm{w}(\operatorname{Exp})}<3 \times M_{\mathrm{w}\left(\mathrm{G}_{1}\right)}$ and non-aggregated character was likewise concluded from the DLS measurements when comparing the $D_{\mathrm{h}}^{\mathrm{n}}$ of the arborescent substrate and the PIC micelles. This assumption allows the calculation of the average number of chains shielding a $\mathrm{G} 1$ core in the micelles. For the five samples deemed to be non-aggregated, the number of DHBC chains per micelle varied from 27 $\mathrm{PAA}_{13}-b$-PHEA ${ }_{150}$ surrounding one G1 core for $f=1$, to 68 molecules for G1@PAA $27-b-\mathrm{PHEA}_{260}$ with $f=3$. The number of DHBC molecules per micelle increased as the amount of copolymer ( $f$ ratio) used in their preparation was increased, which seems reasonable. It is also larger for the $\mathrm{PAA}_{27}-b$-PHEA ${ }_{260}$ sample series in comparison to the $\mathrm{PAA}_{13}-b$-PHEA ${ }_{150}$ samples, in spite of the longer PHEA $_{260}$ segment increasing the DHBC bulkiness. This highlights the dominating influence of the anchoring PAA segment length in determining the number of copolymer chains incorporated in the PIC micelles. 
This document is the Accepted Manuscript version of a Published Work that appeared in final form in Langmuir, 2016, 32(50), 13482-13492, after peer review and technical editing by the publisher. Copyright (C) American Chemical Society. To access the final edited and published work see http://pubs.acs.org/doi/abs/10.1021/acs.langmuir.6b03683

Since the $M_{\mathrm{w}(\operatorname{Exp})}$ determined for PIC micelles G1@PAA $13-b-\mathrm{PHEA}_{150}$ with $f=0.5$ and 0.25 , and G1@PAA $27-b$-PHEA 260 with $f=0.25$ was larger than $M_{\mathrm{w}}$ (Theor.), the micelles clearly flocculated due to the lack of stabilizer within the PIC shell. Contrary to our expectations, the G1@PAA $13-b$-PHEA 5 and $\mathrm{G}_{50} @ \mathrm{PAA}_{27}-b$ PHEA $_{56}$ systems with $f=9$, thought to be aggregated on the basis of the DLS measurements, were found to have $M_{\mathrm{w}(\mathrm{Exp})}<2 \times M_{\mathrm{w}(\mathrm{G})}$. The expected structure of these two assemblies will be further discussed on the basis of their $\rho$-parameter below.

$\rho$-Parameter. The ratio of the gyration and hydrodynamic radii $R_{\mathrm{g}} / R_{\mathrm{h}}$, also known as the $\rho$ parameter, is structure-sensitive and can provide information on the morphology of PIC micelles. For example, $\rho=0.775$ is expected for rigid spheres of uniform density, while $\rho=1.7-2.0$ is typically observed for randomly coiled polymer chains. ${ }^{40}$ However, for particles combining a dense core and partly coiled, less dense chain segments forming the shell, the concentration of the mass within their core can lead to a small radius of gyration, and $\rho$-values below the rigid sphere "limit" are thus often observed, while $\rho$-values close to 0.775 more likely reflect a core-shell structure with a non-homogenous mass density. Thus $\rho$ parameters below the rigid sphere limit $(0.58<\rho<0.61)$ were reported for lightly and moderately cross-linked PBMA microgels in $\mathrm{THF}^{41}$ and $0.61<\rho<0.68$ for spherical PS microgels measured in toluene. ${ }^{42}$ Micelles with PS segregated within the micellar core, surrounded by less dense PMAA segments in a dioxane : water 80 : $20 \mathrm{v} / \mathrm{v}$ solvent mixture had $\rho$-values ranging from 0.37 to o.6. ${ }^{43}$ It is also possible for a core-shell structure to have $\rho>0.775$, as reported for CdS@PS- $b$-PMMA hybrid inorganic-organic core-shell NPs with $\rho=1.3$ in toluene (where both PMMA and PS chain segments were swollen), and with $\rho=1.1$ in acetone (where the PS chains were collapsed). ${ }^{44}$

The DLS data used in the $\rho$-parameter analysis were extrapolated to zero angle at a concentration of $1 \mathrm{mg} \cdot \mathrm{mL}^{-}$ ${ }^{1}$ (ESI S3.3) to determine the hydrodynamic radius $\left(R_{\mathrm{h}}\right)$. The differences observed by extrapolation in comparison to the $90^{\circ}$ data were relatively small in most cases $(11 \%$ on average). Concentration-dependent DLS measurements also revealed that the influence of concentration $\left(0.2-1 \mathrm{mg} \cdot \mathrm{mL}^{-1}\right)$ on the results was negligible, with ca. $1 \%$ variation among the samples. Consequently, only the data obtained at $1 \mathrm{mg} \cdot \mathrm{mL}^{-1}$ were considered in the multi-angle DLS analysis. Since a collapsed core-loose stabilizing shell morphology was postulated earlier for our PIC micelles, the $\rho$-parameter should reflect the relative masses of the $\mathrm{G} 1$ core and shell components. Thus for G1@PAA $27-b$ - $\mathrm{PHEA}_{56}$ with $f=9$, the value $\rho=0.93$ obtained could suggest a core-shell structure. However the unexpectedly large $D_{\mathrm{h}}^{\mathrm{n}}=44 \mathrm{~nm}$ (Table 1) and extrapolated $D_{\mathrm{h}}=57 \mathrm{~nm}\left(2 \times R_{\mathrm{h}}\right.$ in Table 2$)$ vs. $D_{\max } \approx 29 \mathrm{~nm}$ suggest an aggregation pattern corresponding to a mixture of isolated and aggregated species. The $M_{\mathrm{w}(\mathrm{Exp})}$ of these assemblies, being less than $2 \times \overline{M_{\mathrm{w}}\left(\mathrm{G}_{1}\right)}$, most likely results from a dominant population of isolated species in comparison to aggregated species, resulting in an average hydrodynamic diameter larger than that expected for isolated micellar species. The situation is different for $\mathrm{G1} @ \mathrm{PAA}_{13}-b-\mathrm{PHEA}_{50} f=9$, with a very large $\rho=1.97$ and $\overline{M_{\mathrm{w}}(\mathrm{Exp})}=1.4 \times 10^{6} \mathrm{~g} \cdot \mathrm{mol}^{-1}$, slightly larger than $\overline{M_{\mathrm{w}}(\mathrm{Exp})}=1.3 \times 10^{6} \mathrm{~g} \cdot \mathrm{mol}^{-1}$ in the previous case, corresponding to more repulsive interactions (larger $A_{2}$ ) resulting from a denser neutral polymer shell, decreasing the effective hydrodynamic diameter.

The non-aggregated PIC micelles $\mathrm{Gl}_{1} @ \mathrm{PAA}_{13}-b$ PHEA $_{150}$ with $f=3$ and 1 have $\rho=1.46$ and 1.13 , respectively, consistent is with a core-shell structure. These values are indeed well above the rigid dense sphere value, which evidences the large contribution from the mass of swollen block copolymer chains in the shell surrounding the collapsed arborescent core. The protecting shell was likely less dense for $f=1$ than for $f=$

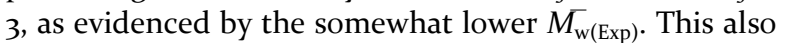
led to smaller $R_{\mathrm{g}}(27.7$ vs. $35.8 \mathrm{~nm})$ and $\rho$ (1.13 vs. 1.46) values for $f=1$, in agreement with the former interpretation of the results.

Among the $R_{\mathrm{g}}$ values obtained for the $\mathrm{G} 1 @ \mathrm{PAA}_{27}-b$ PHEA $_{260}$ system, only the values for $f=3$ and 0.25 are considered reliable since the other two samples had $R_{\mathrm{g}}<$ $\lambda / 20 \sim 15 \mathrm{~nm}$, i.e., dimensions in a range outside the Guinier approximation domain, leading to large errors. On that basis, $\rho=0.8$ obtained for the PIC micelles with $f=3$ is considered consistent with a dense core-swollen shell morphology. It is tempting to come to the same conclusion for $f=1$ and 0.5 , in spite of the large errors expected on the $R_{\mathrm{g}}$ values. Furthermore, the nonaggregated PIC micelles in the $\mathrm{G1} @ \mathrm{PAA}_{27}-b-\mathrm{PHEA}_{260}$ series with $f=3,1$ and 0.5 exhibit a larger $\rho$-value for $f=$ 3. This could be due to a more extended conformation for the copolymer chains in the shell for $f=3$, resulting from increased steric crowding effect in this sample which had the highest molecular weight among all the non-aggregated samples $\left(M_{\mathrm{w}(\operatorname{Exp})}=3.2 \times 10^{6} \mathrm{~g} \cdot \mathrm{mol}^{-1}\right)$.

The aggregates produced by the PIC micelles G1@PAA $\mathrm{PA}_{27}-b-\mathrm{PHEA}_{260}$ with $f=0.25$ were characterized by $\rho=0.57$, suggesting the formation of a dense collapsed core with a relatively small number of $\mathrm{G}_{1}$ molecules $\left(M_{\mathrm{w}(\operatorname{Exp})}=9.7 \times 10^{6} \mathrm{~g} \cdot \mathrm{mol}^{-1}\right)$. Similarly, $\rho=0.89$ obtained for the aggregates $\mathrm{G} 1 @ \mathrm{PAA}_{13}-b$-PHEA $\mathrm{P}_{150} f=0.5$, would correspond to a dense core formed by a larger number of G1 molecules $\left(M_{\mathrm{w}(\operatorname{Exp})}=3.9 \times 10^{7} \mathrm{~g} \cdot \mathrm{mol}^{-1}\right)$, surrounded by a loose shell of PHEA chains. This low $\rho$-parameter value could also be due to the presence of small clusters composed of many PIC micelles as suggested by Qin et al. ${ }^{43}$ The $\rho=1.56$ value obtained for G1@PAA ${ }_{13}-b-$ PHEA $_{150}$ micelles with $f=0.25$, apart from corresponding to even larger aggregates of $\mathrm{G} 1$ molecules $\left(M_{\mathrm{w}(\operatorname{Exp})}=17 \times 10^{7} \mathrm{~g} \cdot \mathrm{mol}^{-}\right.$ $\left.{ }^{1}\right)$, could also correspond to the formation of linear cluster structures, given that $\rho$ is significantly larger than in the previous case. 
This document is the Accepted Manuscript version of a Published Work that appeared in final form in Langmuir, 2016, 32(50), 13482-13492, after peer review and technical editing by the publisher. Copyright (C) American Chemical Society. To access the final edited and published work see http://pubs.acs.org/doi/abs/10.1021/acs.langmuir.6b03683

Second Virial Coefficient. The second virial coefficient $\left(A_{2}\right)$ of polymers in solution obtained from MALLS data is a measure of solvent quality or solventpolymer interactions. All the measured $A_{2}$ values were positive, reflecting favorable interactions between the $\mathrm{OH}$ groups in the PHEA segments of the PIC micelles with the solvent (water). However the range of values observed (from $0.2 \times 10^{-5}$ to $19.3 \times 10^{-5} \mathrm{~cm}^{3} \cdot \mathrm{mol} \cdot \mathrm{g}^{-2}$ ) is indicative of variations in the solvent-polymer interactions. It can be noted that: 1) Values in the highend were observed mostly for systems with $f>1$, regardless of the specific DHBC used, thus reflecting the importance of interactions between the $-\mathrm{OH}$ groups in the PHEA chains and water. 2) Lower $A_{2}$ values were observed for lower $f$ ratios among the series of PIC micelles derived from the same DHBC type. This is also consistent with the first statement. 3) Comparison between the G1@PAA $13-b-\mathrm{PHEA}_{150}$ and $\mathrm{G}_{1} @ \mathrm{PAA}_{27}-b-$ PHEA $_{260}$ PIC micelles at the same $f$ ratio produces the same result: The $A_{2}$ values for the former are smaller than for the latter. This is again related to differences in the number of $-\mathrm{OH}$ groups per PIC micelle. Taking $f=3$ as an example, the G1@PAA $13-b-\mathrm{PHEA}_{150}$ micelle had ca. 5,00o $-\mathrm{OH}$ groups provided by $33 \mathrm{DHBC}$ side chains; $\mathrm{G} 1 @ \mathrm{PAA}_{27}-b-\mathrm{PHEA}_{260}$ carried ca. $17,500-\mathrm{OH}$ groups on 68 DHBC side chains.
The lowest $A_{2}$ values were observed for the aggregated systems as expected: The largest PIC micelle G1@PAA $\mathrm{PA}_{13}$ $b$-PHEA ${ }_{150}$ with $f=0.25\left(M_{\mathrm{w}}=170 \times 10^{6} \mathrm{~g} \cdot \mathrm{mol}^{-1}\right)$ had $A_{2}=$ $0.2 \times 10^{-5} \mathrm{~cm}^{3} \cdot \mathrm{mol} \cdot \mathrm{g}^{-2}$, and so on. There is no obvious correlation between $A_{2}$ and the $\overline{M_{\mathrm{w}}}$ of the aggregated PIC micelles however, presumably because the micelles have a heterogeneous chemical composition between the hydrophobic G1 core and the hydrophilic PAA-PHEA components. Considering the dominating contribution from $-\mathrm{OH} /$ water interactions to $A_{2}$, a correlation was nevertheless found between the number of -OH groups in the molecules and the $A_{2}$ values for non-aggregated systems with $f>1$ (Figure 2a).

pH Responsiveness of the PIC Micelles. The ZP of the PIC micelles G1@PAA $27-b$-PHEA ${ }_{260}$ for $f=0.5$ was $\mathrm{pH}$-dependent. A large negative $\mathrm{ZP}$ (ca. $-27 \mathrm{mV}$ ) was measured at $\mathrm{pH} \geq 7$ (Figure $2 \mathrm{~b}$ ), due to the presence of the $\mathrm{CO}_{2}^{-}$functionalities. The $\mathrm{ZP}$ of the PIC micelles remained fairly constant under basic conditions, indicating complete ionization of the $\mathrm{CO}_{2} \mathrm{H}$ groups beyond $\mathrm{pH}$ 7. The increase in $\mathrm{ZP}$ in the acidic $\mathrm{pH}$ range is ascribed to protonation of the carboxylate groups, yielding the less polar $\mathrm{CO}_{2} \mathrm{H}$ functionalities, and of the amine groups in the $\mathrm{Gl}$ core to yield hydrophilic $\mathrm{NH}^{+}$ derivatives. The isoelectric point of the PIC micelles was around $\mathrm{pH} 4$.
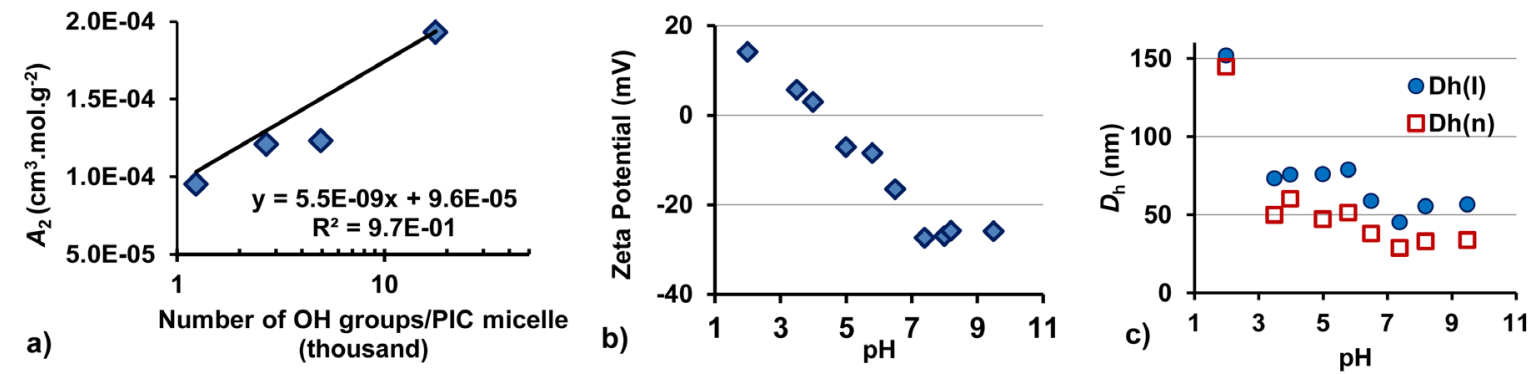

Figure 2. a) Dependence of $A_{2}$ on the number of $-\mathrm{OH}$ groups/PIC micelle. b) Zeta potential and c) Hydrodynamic diameter of PIC micelles G1@PAA $27-b-\mathrm{PHEA}_{260}$ with $f=0.5$ at different $\mathrm{pH}$.

The corresponding $\mathrm{pH}$-dependent variations in $D_{\mathrm{h}}^{\mathrm{I}}$ and $D_{\mathrm{h}}^{\mathrm{n}}$ of the PIC micelles were similar (Figure $2 \mathrm{c}$ ), but the discussion will focus on the trends observed in $D_{\mathrm{h}}^{\mathrm{n}}$. At $\mathrm{pH} 7.4$ the number-weighted hydrodynamic diameter was $28.5 \mathrm{~nm}$. Slight swelling of the PIC micelles to ca. 33 $\mathrm{nm}$ at $\mathrm{pH}$ 8-9.5 was likely caused by electrostatic repulsion between the $\mathrm{CO}_{2}{ }^{-}$groups, even at higher ionic strengths after the addition of o.1 $\mathrm{M} \mathrm{NaOH}$. The hydrodynamic diameter almost doubled as the $\mathrm{pH}$ was decreased from 7.4 to 5.8 , and tripled at $\mathrm{pH}$ to 2 , indicating the formation of aggregates. At the isoelectric point ( $\mathrm{pH}_{4}$ ) the PIC micelles formed small clusters, but no PIC micelle dissociation was observed within the $\mathrm{pH}$ range tested. The variations in $\mathrm{ZP}$ and size were reversible over the range of $\mathrm{pH} \geq 7$ (isolated structures), while between $3.5 \leq \mathrm{pH} \leq 6.5$ small clusters formed that persisted even if the $\mathrm{pH}$ was subsequently brought back to 7 .
Atomic Force Microscopy. The bare Gi substrate, deposited from acidic solutions ( $\mathrm{pH}_{4}$ ), exhibited illdefined morphologies because the arborescent copolymer flattened extensively on mica (visible more clearly in the phase image of Figure 3, column 1), presumably due to strong electrostatic interactions between the protonated G1 and the negatively charged mica. Both the molecular diameter measured on the AFM image (ca. $43 \mathrm{~nm}$, larger than the $D_{\mathrm{h}}^{\mathrm{I}}=29 \mathrm{~nm}$ in acidic solutions) and the height (ca. $1.9 \mathrm{~nm}$ ) obtained by section analysis of the height image confirm strong flattening of the molecules. It is noteworthy that the PIC micelles obtained after complexation appeared as uniformly distributed, almost spherical particles with a narrow size distribution on the mica surface. The spherical morphology of the PIC micelles, shown in the $3 \mathrm{D}$ images and in section analysis of the images (Figure 3, column 2), are attributed in part to electrostatic 
This document is the Accepted Manuscript version of a Published Work that appeared in final form in Langmuir, 2016, 32(50), 13482-13492, after peer review and technical editing by the publisher. Copyright $@$ American Chemical Society. To access the final edited and published work see http://pubs.acs.org/doi/abs/10.1021/acs.langmuir.6b03683

repulsions between the PIC micelles and mica, both negatively charged. Section analysis reveals a particle diameter for the solid PIC micelles of $27 \mathrm{~nm}$ (close to $D_{\mathrm{h}}^{\mathrm{n}}$ $=26 \mathrm{~nm}$ measured in the aqueous dispersions), and a particle height of ca. $2.3 \mathrm{~nm}$.

The phase lag of the cantilever oscillations with respect to the applied force is sensitive to variations in composition, adhesion, friction, viscoelasticity, as well as other factors. ${ }^{45}$ Since the pioneering work of Leclère et al., ${ }^{46-47}$ darker domains of AFM phase images have been assigned to "soft" materials in several reports, ${ }^{48-49}$ whilst the bright regions were ascribed to stiffer domains. ${ }^{49}$
The surface of PIC micelles changed dramatically in comparison to the G1 substrate, from a "stiff" GoPS- $g$ $\mathrm{P}_{2}$ VP matrix appearing in bright color to a dark "soft" coating layer. This is interpreted as a transition from a glassy PS- $g$ - $\mathrm{P}_{2}$ VP core to the acrylic hydrophilic PHEA phase of lower $T_{\mathrm{g}}$, also potentially plasticized by adsorbed water. The size, size distribution and uniformity of the PIC particles assessed by AFM analysis provide strong evidence for the success of the polyion complexation process using DHBC $\mathrm{PAA}_{27}-b-\mathrm{PHEA}_{260}$.
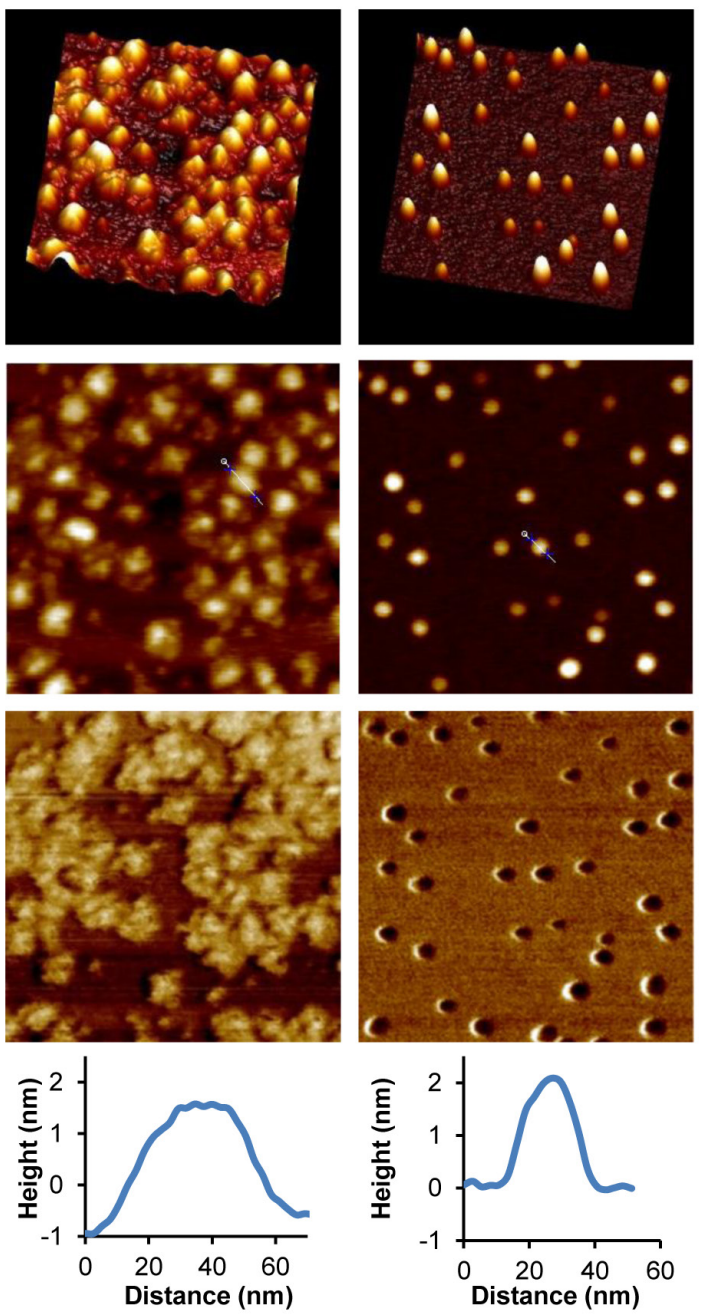
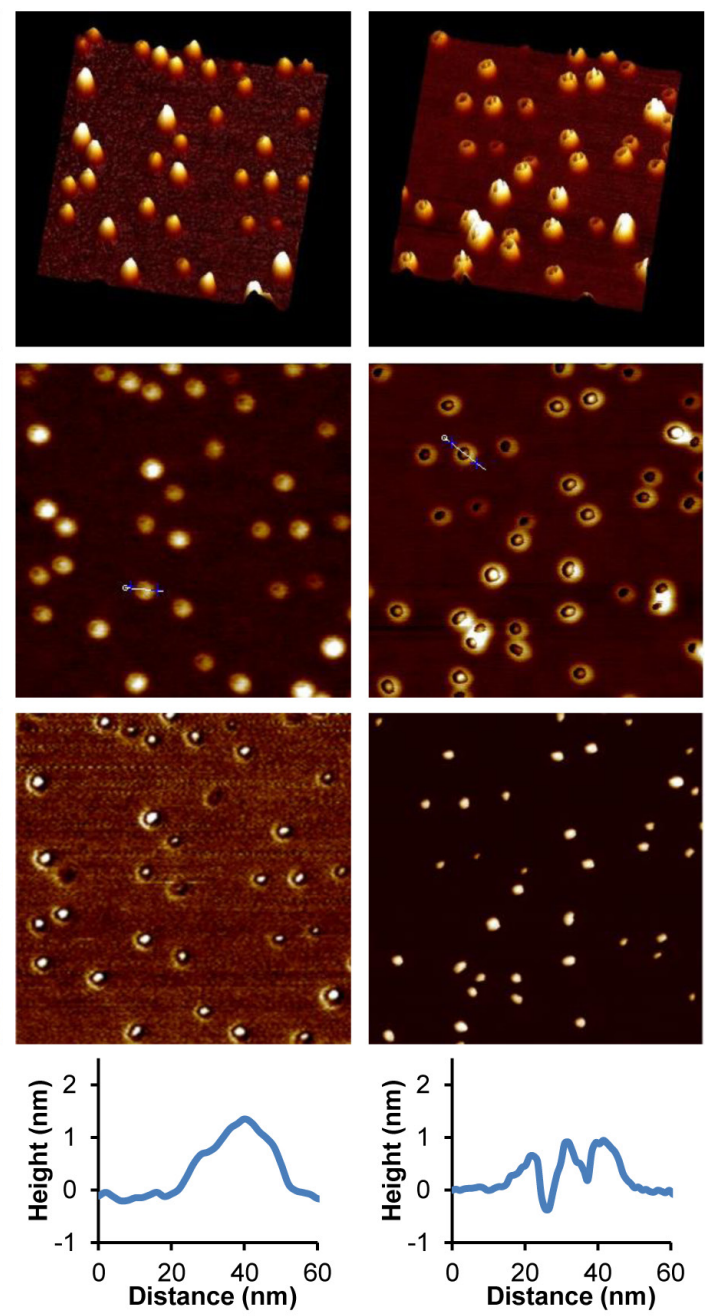

Figure 3. 3D images (row 1), height (row 2), phase AFM images (row 3) and section analysis (row 4) for the G1 substrate (column 1), G1@PAA $27-b-\mathrm{PHEA}_{260}$ with $f=0.5$ at set-points ratios of 0.96 (column 2), 0.92 (column 3), and o.86 (column 4). The scale of all the images is $400 \times 400 \mathrm{~nm}^{2}$.

In Tapping Mode $^{\mathrm{TM}}$, the oscillating force applied during scanning is related to the ratio of the set-point amplitude to the free-oscillation amplitude of the cantilever, usually defined as the set-point ratio. ${ }^{50}$ For set-point ratios close to but less than 1, a low force is applied on the surface whilst at smaller set-point ratios, the AFM tip interacts more strongly with the sample. ${ }^{49}$
By tuning the amplitude set-point and thus varying the interaction forces between the AFM tip and the particles, the morphology of PIC micelle can be probed. The PIC micelles (Figure 3) appear as spherical particles surrounded by a layer of "soft" PHEA (in darker color) at a set-point ratio of 0.96 (column 2). A stronger force applied at a set-point ratio of 0.92 (column 3) reveals the 
This document is the Accepted Manuscript version of a Published Work that appeared in final form in Langmuir, 2016, 32(50), 13482-13492, after peer review and technical editing by the publisher. Copyright (C) American Chemical Society. To access the final edited and published work see http://pubs.acs.org/doi/abs/10.1021/acs.langmuir.6b03683

"hard" PS core (bright color) inside each PIC micelle, with a surrounding softer ring (darker color), thus confirming the core-shell morphology of the micelles. This structure was further confirmed by the "mountainlike" topology of PIC micelles (shown in the ${ }_{3} \mathrm{D}$ images and the section analyses). When the set-point ratio was further decreased to o.86 (column 4), at which point the PIC micelles appeared in a "sunny side up" egg-like morphology on the height AFM images, only the rigid PS component could be detected in the phase image. It may thus be concluded beyond any doubt that AFM analysis confirmed the formation of a DHBC stabilizing layer on the $\mathrm{G} 1$ arborescent substrate, as deduced from the DLS and MALLS measurements.

Cytotoxicity Assessment. Due to the hydrophobicity of PS and $\mathrm{P}_{2} \mathrm{VP}$ at physiological $\mathrm{pH}$, these polymers would be most likely isolated within the core of the PIC micelle, thus shifting the need for biocompatibility to the protecting shell, namely PAA and PHEA in our case. PAA has been used as an adhesive and surface-protective agent in dentistry, in eye drops,
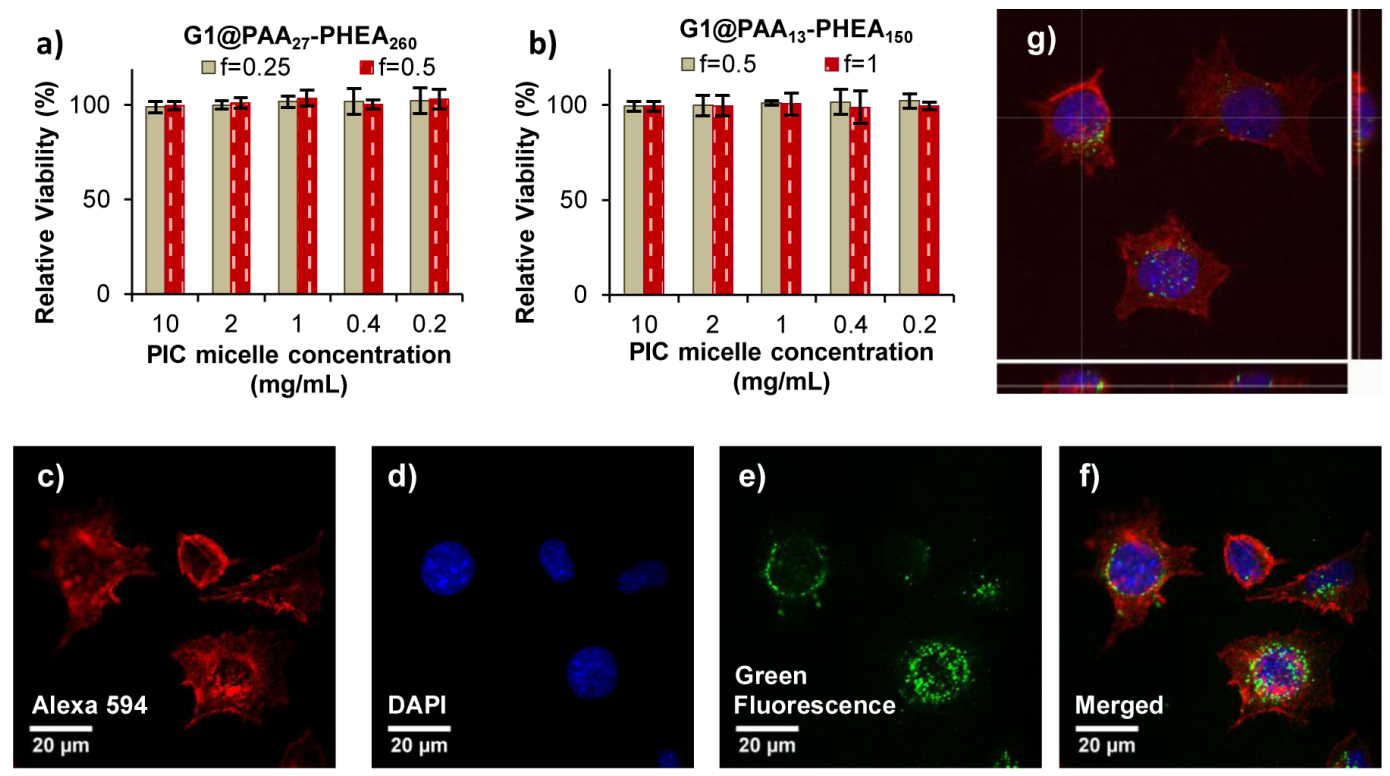

Figure 4. a) and b) Cytotoxicity profiles for PIC micelles G1@PAA-b-PHEA at various $f$ ratios with the L929 cells determined via MTS assay at different concentrations after $48 \mathrm{~h}$ of incubation. Cell viability is expressed as the mean value and the standard deviation from three independent experiments, each with four replicates per condition, relatively to untreated cells ( $100 \%$ control); c) to f) confocal laser scanning microscopy images; and g) $3 \mathrm{D}$ construction and $x z, y z$ sections for L929 cells treated with PIC* micelles $\left(2 \mathrm{mg} \cdot \mathrm{mL}^{-1}, 24 \mathrm{~h}\right.$ incubation).

Cell Internalization Study. A preliminary qualitative cell internalization study by confocal laser scanning microscopy (CLSM) used the same cell line as the cytotoxicity assessment. The cytoskeleton F-actin was labeled with phalloidin (red), while the nuclei were labeled with DAPI (blue), as shown in Figure SI-12 (for L929 cells not treated with PIC micelles), and in Figure $4 \mathrm{C}$ to $\mathrm{f}$ (for L929 cells treated with the PIC* micelles). The $\mathrm{PIC}^{*}$ micelles labeled with the fluorescent probe fluoresceinamine were visualized as green fluorescent species. suppositories, capsules, wart creams, and in ophthalmic gels. $^{51-52}$ PHEA has biocompatibility including low cytotoxicity and good cell compatibility, ${ }^{29-30}$ similarly to the more widespread poly(2-hydroxyethyl methacrylate). PHEA-based materials have been used in controlled release drug delivery ${ }^{53}$ and in cell culture without significant cytotoxicity. ${ }^{54}$ Within the range tested (from 0.2 to $10 \mathrm{mg} \cdot \mathrm{mL}^{-}$), micelles displayed cytotoxicity on the L929 cells (Figure $4 \mathrm{a}, \mathrm{b})$, despite their different sizes $\left(D_{\mathrm{h}}^{\mathrm{I}}\right.$ $=42$ and $87 \mathrm{~nm}$ for $\mathrm{Gl}_{1} @ \mathrm{PAA}_{27}-b-\mathrm{PHEA}_{260} f=0.5$ and .25; $D_{\mathrm{h}}^{\mathrm{I}}=46$ and $104 \mathrm{~nm}$ for G1@PAA $\mathrm{P}_{13}-b-\mathrm{PHEA}_{150} f=1$ 0.5). Even after a 48-h incubation period, the L929 undergoing mitosis indicating the proliferation capability of the cells after exposure to the NPs. The good cell viability is attributed to the high hydrophilicity, biocompatibility and electrostatic neutrality of the PHEA shell. 
This document is the Accepted Manuscript version of a Published Work that appeared in final form in Langmuir, 2016, 32(50), 13482-13492, after peer review and technical editing by the publisher. Copyright @ American Chemical Society. To access the final edited and published work see http://pubs.acs.org/doi/abs/10.1021/acs.langmuir.6b03683

fluorescent dots below optical resolution $(\sim 300 \mathrm{~nm})$, thereby evidencing their non-aggregation within the cytoplasm of cells and their integrity: The PHEA shell may prevent degradation induced by proteases and other enzymes existing in the low $\mathrm{pH}$ environment of late endosomes and lysosomes. The cells contained variable numbers of PIC micelles. The $3 \mathrm{D}$ construction from a 50 CLSM image stack (Figure 4g) clearly shows the location of the PIC micelles inside the cytoplasm, although some also stayed at the periphery of the nuclear membrane.

\section{CONCLUSIONS}

PAA- $b$-PHEA DHBCs with four different block lengths were synthesized by ATRP, and for the first time employed as polymeric stabilizers for $\mathrm{P}_{2} \mathrm{VP}$-containing arborescent substrate cores through polyion complexation in water. Control over the size and structure of the PIC micelles, from large flocculated species to stable isolated (non-aggregated) entities, was accomplished by tuning the density of the polymer stabilizing layer, either by varying the DHBC stoichiometry or the length of the PAA anchoring block, and most notably by varying the length of the nonionic PHEA block. Slightly better stability was achieved by decreasing the PAA block length from 27 to 13 units at constant length of the PHEA block, which presumably led to increased coverage by the DHBC on the surface of the micelles. Short PHEA tails were insufficiently bulky to impart good colloidal stability, while most effective stabilization was achieved when the length of the nonionic segments was increased to 260 units, even for the sub-stoichiometric complexation ratio $f=0.5$. Evidence for isolated vs. aggregated structures formation was obtained by: i) comparing the hydrodynamic diameter of the micelles with the dimensions calculated for the collapsed core and ii) obtaining molar mass $\left(M_{\mathrm{w}}\right)$ and gyration-to-hydrodynamic radii ratio ( $\rho$-parameter) values from static and dynamic light scattering measurements. The second virial coefficient $A_{2}$ obtained by MALLS also highlighted the dominating role of $\mathrm{OH} /$ water interactions. The success of the complexation process and the core-shell morphology of PIC micelles were confirmed by imaging of the soft shell of PHEA surrounding the stiff $\mathrm{G}$ l core through variations in the amplitude set-point in Tapping Mode ${ }^{\mathrm{TM}}$ AFM.

None of the PIC micelles incorporating one or multiple G1 arborescent core(s) and a shell of PAA- $b$ PHEA (tested at concentrations of up to $10 \mathrm{mg} \cdot \mathrm{mL}^{-1}$ ) had significant cytotoxicity for L929 cells after $48 \mathrm{~h}$ of incubation, in spite of their different coating densities and sizes. The good colloidal stability and noncytotoxicity of the PIC micelles are ascribed to their good biocompatibility and hydrophilicity, and to the neutrality of the PHEA shell. In spite of being negatively charged, fluorescently labeled PIC* micelles were successfully internalized through the L929 cell membrane to reach the cytoplasmic compartment and perinuclear region. The response of PIC micelles to $\mathrm{pH}$ variations could be useful for applications such as the preparation of metallic or metal oxide NPs. A forthcoming article will describe the preparation of magnetic PIC micelles, making use of their GoPS- $g$-P2VP core as chelator for iron oxide precursors, and as templating medium for the synthesis of inorganic nanoparticles. The PIC process using PAA- $b$-PHEA to stabilize hydrophobic P2VP-containing arborescent copolymers can be applied to different $\mathrm{P}_{2} \mathrm{VP}$ copolymers, or to more complex arborescent materials (e.g. hybrid organic-inorganic systems).

\section{ASSOCIATED CONTENT}

\section{Supporting Information}

The Supporting Information is available free of charge on the ACS Publications website http://pubs.acs.org/ at DOI: 10.1021/acs.langmuir.6bo3683

Detailed procedures for the synthesis and characterization of the double-hydrophilic block copolymers and the PIC micelles. Methodology for biocompatibility and cell internalization assessment (PDF).

\section{AUTHOR INFORMATION}

Corresponding Authors. *E-mail:

olivier.sandre@enscbp.fr; gauthier@uwaterloo.ca

Author Contributions. M. G. and O. S. conceived the overall approach and supervised the project. M.-C. D.P.G. supervised the cell culture assessment. V. T. A. N. designed and performed experiments, analyzed data and wrote this manuscript, which was corrected by M.-C. D.P.-G., O. S. and M. G.

Funding Sources. The authors thank the IDS-FunMat, Erasmus Mundus Program of the European Union, the University of Waterloo, the Agence Nationale de la Recherche (ANR-13-BSo8-oo17 MagnetoChemoBlast), and the Natural Sciences and Engineering Research Council of Canada (NSERC) for their financial support.

\section{ACKNOWLEDGEMENTS}

We thank DE. Emmanuel Ibarboure (LCPO), DE. Patrick Garrigue (ENSCBP), and Pr. Neso Sojic (ENSCBP) for assistance with AFM, DE. Nicolas Guidolin (LCPO) for assistance with MALLS, and Dr. Sandra Ormenese (Imaging and flow cytometry platform - GIGA-R) for her help with confocal laser scanning microscopy.

\section{ABBREVIATIONS}

AFM, atomic force microscopy; CLSM, confocal laser scanning microscopy; DLS, dynamic light scattering; 
This document is the Accepted Manuscript version of a Published Work that appeared in final form in Langmuir, 2016, 32(50), 13482-13492, after peer review and technical editing by the publisher. Copyright (C) American Chemical Society. To access the final edited and published work see http://pubs.acs.org/doi/abs/10.1021/acs.langmuir.6b03683

DHBC, double-hydrophilic block copolymer; MALLS, multi-angle laser light scattering; NP, nanoparticle; $\mathrm{P}_{2} \mathrm{VP}$, poly(2-vinylpyridine); PAA, poly(acrylic acid); PEO, poly(ethylene oxide); PHEA, poly(2-hydroxyethyl acrylate); PIC, polyion complex; PMAA, poly(methacrylic acid); PS, polystyrene; VDW, van der Waals; ZP, zeta potential.

\section{REFERENCES AND NOTES}

(1) Wu, L.; Zhang, J.; Watanabe, W., Physical and Chemical Stability of Drug Nanoparticles. Advanced Drug Delivery Reviews 2011, 63 (6), 456-469.

(2) Patravale, V. B.; Date, A. A.; Kulkarni, R. M., Nanosuspensions: A Promising Drug Delivery Strategy. Journal of Pharmacy and Pharmacology 2004, 56 (7), 827-840.

(3) Gebhart, C. L.; Kabanov, A. V., Perspectives on Polymeric Gene Delivery. Journal of Bioactive and Compatible Polymers 2003, 18 (2), 147-166.

(4) Ideta, R.; Tasaka, F.; Jang, W.-D.; Nishiyama, N.; Zhang, G.-D.; Harada, A.; Yanagi, Y.; Tamaki, Y.; Aida, T.; Kataoka, K., Nanotechnology-Based Photodynamic Therapy for Neovascular Disease Using a Supramolecular Nanocarrier Loaded with a Dendritic Photosensitizer. Nano Letters 2005, 5 (12), 2426-2431.

(5) Bronich, T. K.; Keifer, P. A.; Shlyakhtenko, L. S.; Kabanov, A. V., Polymer Micelle with Cross-Linked Ionic Core. Journal of the American Chemical Society 2005, 127 (23), 8236-8237.

(6) Gambinossi, F.; Mylon, S. E.; Ferri, J. K., Aggregation Kinetics and Colloidal Stability of Functionalized Nanoparticles. Advances in Colloid and Interface Science 2015, 222, 332-349.

(7) Napper, D. H., Polymeric Stabilization of Colloidal Dispersions. Academic Press London: 1983; Vol. 7.

(8) Ishikawa, Y.; Aoki, N.; Ohshima, H., Colloidal Stability of Aqueous Polymeric Dispersions: Effect of Water Insoluble Excipients. Colloids and Surfaces B: Biointerfaces 2005, 45 (1), 35-41.

(9) Harada, A.; Kataoka, K., Formation of Polyion Complex Micelles in an Aqueous Milieu from a Pair of Oppositely-Charged Block Copolymers with Poly(ethylene glycol) Segments. Macromolecules 1995, 28 (15), 5294-5299.

(10) Kabanov, A. V.; Bronich, T. K.; Kabanov, V. A.; Yu, K.; Eisenberg, A., Soluble Stoichiometric Complexes from $\operatorname{Poly}(N$-ethyl-4-vinylpyridinium) Cations and Poly(ethylene oxide)-block-Polymethacrylate Anions. Macromolecules 1996, 29 (21), 6797-6802.

(11) Cohen Stuart, M. A.; Besseling, N. A. M.; Fokkink, R. G., Formation of Micelles with Complex Coacervate Cores. Langmuir 1998, 14 (24), 6846-6849.

(12) de Vries, R.; Cohen Stuart, M., Theory and Simulations of Macroion Complexation. Current Opinion in Colloid E Interface Science 2006, 11 (5), 295-301.

(13) Zhou, X.; Goh, S. H.; Lee, S. Y.; Tan, K. L., XPS and

FTi.r. Studies of Interactions in Poly(carboxylic
acid)/Poly(vinylpyridine) Complexes. Polymer 1998, 39 (16), 3631-3640.

(14) Lefèvre, N.; Fustin, C.-A.; Varshney, S. K.; Gohy, J.F., Self-Assembly of Block Copolymer Complexes in Organic Solvents. Polymer 2007, 48 (8), 2306-2311.

(15) Zhang, W.; Shi, L.; Miao, Z. J.; Wu, K.; An, Y., CoreShell-Corona Micellar Complexes between Poly(ethylene glycol)-block-Poly(4-vinyl pyridine) and Polystyrene-block-Poly(acrylic acid). Macromolecular Chemistry and Physics 2005, 206 (23), 2354-2361.

(16) Gohy, J.-F.; Khousakoun, E.; Willet, N.; Varshney, S. K.; Jérôme, R., Segregation of Coronal Chains in Micelles Formed by Supramolecular Interactions. Macromolecular Rapid Communications 2o04, 25 (17), 1536-1539.

(17) Hameed, N.; Guo, Q., Nanostructure and Hydrogen Bonding in Interpolyelectrolyte Complexes of Poly( $\varepsilon$ caprolactone)-block-Poly(2-vinyl pyridine) and Poly(acrylic acid). Polymer 20o8, 49 (24), 5268-5275.

(18) Zhang, W.; Shi, L.; An, Y.; Wu, K.; Gao, L.; Liu, Z.; Ma, R.; Meng, Q.; Zhao, C.; He, B., Adsorption of Poly(4vinyl pyridine) Unimers into Polystyrene-blockPoly(acrylic acid) Micelles in Ethanol Due to Hydrogen Bonding. Macromolecules 2004, 37 (8), 2924-2929.

(19) Warnant, J.; Marcotte, N.; Reboul, J.; Layrac, G.; Aqil, A.; Jerôme, C.; Lerner, D. A.; Gérardin, C., Physicochemical Properties of $\mathrm{pH}$-Controlled Polyion Complex (PIC) Micelles of Poly(acrylic acid)-Based Double Hydrophilic Block Copolymers and Various Polyamines. Analytical and Bioanalytical Chemistry 2012, 403 (5), 1395-1404.

(20) Gohy, J.-F.; Varshney, S. K.; Jérôme, R., Morphology of Water-Soluble Interpolyelectrolyte Complexes Formed by Poly(2-vinylpyridinium)-block-Poly(ethylene oxide) Diblocks and Poly(4-styrenesulfonate) Polyanions. Macromolecules 2001, 34 (9), 2745-2747.

(21) Gohy, J.-F.; Varshney, S. K.; Jérôme, R., WaterSoluble Complexes Formed by Poly(2-vinylpyridinium)block-Poly(ethylene oxide) and Poly(sodium methacrylate)-block-Poly(ethylene oxide) Copolymers. Macromolecules 2001, 34 (10), 3361-3366.

(22) Sfika, V.; Tsitsilianis, C.; Kiriy, A.; Gorodyska, G.; Stamm, M., pH Responsive Heteroarm Starlike Micelles from Double Hydrophilic ABC Terpolymer with Ampholitic A and C Blocks. Macromolecules 2oo4, 37 (25), 9551-9560.

(23) Wang, Y.; Wei, G.; Wen, F.; Zhang, X.; Zhang, W.; Shi, L., Adsorption of Poly $(N$-isopropylacrylamide-co-4vinylpyridine) onto Core-Shell Poly(styrene-comethylacrylic acid) Microspheres. European Polymer Journal 2008, 44 (4), 1175-1182.

(24) One of the referees expressed strong objection to using "PIC micelle" terminology to describe the selfassembled structures obtained in the present investigation, insisting that they rather be described as "polymer complex colloids", given the high molecular weight of the arborescent polymers used to prepare them. We insist on using this particular nomenclature 
This document is the Accepted Manuscript version of a Published Work that appeared in final form in Langmuir, 2016, 32(50), 13482-13492, after peer review and technical editing by the publisher. Copyright (C) American Chemical Society. To access the final edited and published work see http://pubs.acs.org/doi/abs/10.1021/acs.langmuir.6b03683

however, considering that 1) under optimal conditions, the self-assembled structures incorporate one single arborescent polymer molecule with well-defined characteristics (narrow molecular weight distribution, controlled branching density, etc.), as opposed to a solid particle, 2) coupling of the double-hydrophilic block copolymer with the hydrophobic arborescent substrate is achieved via electrostatic interactions, and 3) the amphiphilic character of the assemblies is indeed analogous to other micellar species such as those obtained by the self-assembly of amphiphilic block copolymers, as well as amphiphilic dendritic structures. The use of the term "micelles" to describe different types of dendritic amphiphiles (the closest analogues to the systems being investigated) is indeed widespread in the literature, as demonstrated by the following four reviews on these types of amphiphilic constructs.

(25) Fan, X.; Li, Z.; Loh, X. J., Recent Development of Unimolecular Micelles as Functional Materials and Applications. Polymer Chemistry 2016, 7 (38), 5898-5919. (26) Ambade, A. V.; Savariar, E. N.; Thayumanavan, S., Dendrimeric Micelles for Controlled Drug Release and Targeted Delivery. Molecular Pharmaceutics 2005, 2 (4), 264-272.

(27) Wang, D.; Deraedt, C.; Ruiz, J.; Astruc, D., Magnetic and Dendritic Catalysts. Accounts of Chemical Research 2015, 48 (7), 1871-1880.

(28) Lukowiak, M. C.; Thota, B. N. S.; Haag, R., Dendritic Core-Shell Systems as Soft Drug Delivery Nanocarriers. Biotechnology Advances 2015, 33 (6, Part 3), 1327-1341.

(29) Lin, M.; Xu, P.; Zhong, W., Preparation, Characterization, and Release Behavior of AspirinLoaded Poly(2-hydroxyethyl acrylate)/Silica Hydrogels. Journal of Biomedical Materials Research, Part B: Applied Biomaterials 2012, 100B (4), 1114-1120.

(30) Hoogenboom, R.; Popescu, D.; Steinhauer, W.; Keul, H.; Möller, M., Nitroxide-Mediated Copolymerization of 2-Hydroxyethyl Acrylate and 2-Hydroxypropyl Acrylate: Copolymerization Kinetics and Thermoresponsive Properties. Macromolecular Rapid Communications 2009, 30 (23), 2042-2048.

(31) Gauthier, M.; Munam, A., Arborescent Polystyrenegraft-Poly(2-vinylpyridine) Copolymers: Solution Polyelectrolyte Behavior. RSC Advances 2012, 2 (7), 31003108.

(32) Choi, J.; Rubner, M. F., Influence of the Degree of Ionization on Weak Polyelectrolyte Multilayer Assembly. Macromolecules 2004, 38 (1), 116-124.

(33) Burke, S. E.; Barrett, C. J., Acid-Base Equilibria of Weak Polyelectrolytes in Multilayer Thin Films. Langmuir 2003, 19 (8), 3297-3303.

(34) Zhao, H.; Liu, S.; Jiang, M.; Yuan, X. f.; An, Y.; Liu, L., Acid Terminated PS: not Polyion Micelle-like Particles Formed by Carboxylic Acid-Terminated Polystyrene and Poly(4-vinyl pyridine) in Chloroform/Methanol Mixed Solution. Polymer 2ooo, 41 (7), 2705-2709.
(35) Xiong, D. a.; He, Z.; An, Y.; Li, Z.; Wang, H.; Chen, X.; Shi, L., Temperature-Responsive Multilayered Micelles Formed from the Complexation of PNIPAM- $b$ $\mathrm{P}_{4} \mathrm{VP}$ Block-Copolymer and PS- $b$-PAA Core-Shell Micelles. Polymer 2008, 49 (10), 2548-2552.

(36) Mori, H.; Müller, A. H. E.; Klee, J. E., Intelligent Colloidal Hybrids via Reversible pH-Induced Complexation of Polyelectrolyte and Silica Nanoparticles. Journal of the American Chemical Society 2003, 125 (13), 3712-3713.

(37) Huang, Z.; Alonzo, J.; Liu, M.; Ji, H.; Yin, F.; Smith, G. D.; Mays, J. W.; Kilbey, S. M.; Dadmun, M. D., Impact of Solvent Quality on the Density Profiles of Looped Triblock Copolymer Brushes by Neutron Reflectivity Measurements. Macromolecules 2008, 41 (5), 1745-1752.

(38) Schaefer, D. W.; Han, C. C., Quasielastic Light Scattering from Dilute and Semidilute Polymer Solutions. In Dynamic Light Scattering: Applications of Photon Correlation Spectroscopy, Pecora, R., Ed. Springer US: Boston, MA, 1985; pp 181-243.

(39) Johnson Jr., C. S.; Gabriel, D. A., Classical Light Scattering. In Laser Light Scattering, Dover: New York, 1994; pp 22-71.

(40) Schmidt, M.; Burchard, W., Translational Diffusion and Hydrodynamic Radius of Unperturbed Flexible Chains. Macromolecules 1981, 14 (1), 210-211.

(41) Kunz, D.; Thurn, A.; Burchard, W., Dynamic light scattering from spherical particles. Colloid and Polymer Science 1983, 261 (8), 635-644.

(42) Antonietti, M.; Bremser, W.; Schmidt, M., Microgels: Model Polymers for the Crosslinked State. Macromolecules 1990, 23 (16), 3796-3805.

(43) Qin, A.; Tian, M.; Ramireddy, C.; Webber, S. E.; Munk, P.; Tuzar, Z., Polystyrene-Poly(methacrylic acid) Block Copolymer Micelles. Macromolecules 1994, 27 (1), 120-126.

(44) Guo, Y.; Moffitt, M. G., Semiconductor Quantum Dots with Environmentally Responsive Mixed Polystyrene/Poly(methyl methacrylate) Brush Layers. Macromolecules 2007, 40 (16), 5868-5878.

(45) Schmitz, I.; Schreiner, M.; Friedbacher, G.; Grasserbauer, M., Phase Imaging as an Extension to Tapping Mode AFM for the Identification of Material Properties on Humidity-Sensitive Surfaces. Applied Surface Science 1997, 115 (2), 190-198.

(46) Leclère, P.; Lazzaroni, R.; Brédas, J. L.; Yu, J. M.; Dubois, P.; Jérôme, R., Microdomain Morphology Analysis of Block Copolymers by Atomic Force Microscopy with Phase Detection Imaging. Langmuir 1996, 12 (18), 4317-4320.

(47) Leclère, P.; Moineau, G.; Minet, M.; Dubois, P.; Jérôme, R.; Brédas, J. L.; Lazzaroni, R., Direct Observation of Microdomain Morphology in "AllAcrylic" Thermoplastic Elastomers Synthesized via Living Radical Polymerization. Langmuir 1999, 15 (11), 3915-3919.

(48) Xu, L.-C.; Runt, J.; Siedlecki, C. A., Dynamics of Hydrated Polyurethane Biomaterials: Surface 
This document is the Accepted Manuscript version of a Published Work that appeared in final form in Langmuir, 2016, 32(50), 13482-13492, after peer review and technical editing by the publisher. Copyright (C) American Chemical Society. To access the final edited and published work see http://pubs.acs.org/doi/abs/10.1021/acs.langmuir.6b03683

Microphase Restructuring, Protein Activity and Platelet Adhesion. Acta Biomaterialia 2010, 6 (6), 1938-1947.

(49) Raghavan, D.; Gu, X.; Nguyen, T.; VanLandingham, M.; Karim, A., Mapping Polymer Heterogeneity Using Atomic Force Microscopy Phase Imaging and Nanoscale Indentation. Macromolecules 2000, 33 (7), 2573-2583.

(50) Eaton, P.; West, P., Atomic Force Microscopy. Oxford University: New York, 2010; p 248.

(51) Prati, C.; Pashley, D. H.; Montanari, G., Hydrostatic Intrapulpal Pressure and Bond Strength of Bonding Systems. Dental Materials 1991, 7 (1), 54-58.

(52) Seldon, H. L.; Dahm, M. C.; Clark, G. M.; Crowe, S., Silastic with Polyacrylic Acid Filler: Swelling Properties, Biocompatibility and Potential Use in Cochlear Implants. Biomaterials 1994, 15 (14), 1161-1169.

(53) Arun, A.; Reddy, B. S. R., In Vitro Drug Release Studies of 2-Hydroxyethyl Acrylate or 2-Hydroxypropyl Methacrylate-4-\{(1E,4E)-5-[4-(acryloyloxy)phenyl]-3-

oxopenta-1,4-dienyl $\}$ phenyl Acrylate Copolymer Beads.
Journal of Biomedical Materials Research, Part B: Applied Biomaterials 2005, 73B (2), 291-300.

(54) Martínez-Ramos, C.; Lainez, S.; Sancho, F.; García Esparza, M. A.; Planells-Cases, R.; García Verdugo, J. M.; Gómez Ribelles, J. L.; Salmerón Sánchez, M.; Monleón Pradas, M.; Barcia, J. A.; Soria, J. M., Differentiation of Postnatal Neural Stem Cells into Glia and Functional Neurons on Laminin-Coated Polymeric Substrates. Tissue Engineering Part A 2008, 14 (8), 1365-1375.

(55) Iversen, T.-G.; Skotland, T.; Sandvig, K., Endocytosis and Intracellular Transport of Nanoparticles: Present Knowledge and Need for Future Studies. Nano Today 2011, 6 (2), 176-185.

(56) Zhang, L. W.; Monteiro-Riviere, N. A., Mechanisms of Quantum Dot Nanoparticle Cellular Uptake. Toxicological Sciences 2009, 110 (1), 138-155. 